\title{
POLÍTICA ECONÓMICA REGIONAL E IMPACTOS SOCIALES: EL CASO DE LA MAQUINARIA AGRÍCOLA ARGENTINA*
}

\author{
Recibido: 09 de mayo de 2017 • Aprobado: 20 de febrero de 2018
}

DOI: 10.22395/seec.v21n46a2

\author{
José Vigil ${ }^{* *}$ \\ Melina Sacchi**
}

\section{RESUMEN}

El artículo propone una exploración empírica en Argentina sobre la manera en que se conforma una región económica, la forma como en dicha construcción se articulan políticas nacionales y regionales, y las relaciones que existen entre la dinámica económica de la región conformada y sus impactos sociales. Así entonces, se analiza la región argentina de producción de maquinaria agrícola ubicada en el corazón de la pampa húmeda argentina, que "emergió" con mayor fuerza en el mapa político y económico argentino durante el nuevo modelo desarrollista que intentó un proceso de reindustrialización de la economía a partir de 2001; ello permite mostrar que la región tuvo un comportamiento favorable en sus indicadores sociales.

\section{PALABRAS CLAVE}

Desarrollo económico regional; planificación del desarrollo regional; relaciones intergubernamentales, impactos sociales; Argentina.

\section{CLASIFICACIÓN JEL}

O18, R19, R58, H70

\section{CONTENIDO}

Introducción; 1. Políticas económicas, instituciones y articulaciones múltiples; 2. La medición del desarrollo y las variables de la dinámica social de la región de la MA argentina; 3. La dinámica socioeconómico-demográfica de la región de la MA argentina; 4. Reflexiones sobre las políticas de desarrollo económico regional; Bibliografía.

\footnotetext{
* Este artículo de investigación es resultado del proyecto de investigación PICT 2012/2449, "Regiones, instituciones y prácticas de poder. El caso de la maquinaria agrícola (Argentina)", financiado por la Agencia Nacional de Promoción Científica y Tecnológica de Argentina, y dirigido por José Vigil en el Instituto de Investigación Estado Territorio y Economía de la Universidad Nacional del Litoral (Argentina). Se agradecen los valiosos comentarios de tres árbitros anónimos que han enriquecido la versión final de este trabajo.

** Abogado, Universidad Nacional del Litoral, Santa Fe, Argentina. Magíster en ciencia política, Flacso Argentina. Candidato a PhD, Departamento de Geografía, Durham University, Inglaterra. Profesor, Investigador y Coordinador del Instituto de Investigación Estado Territorio y Economía de la Facultad de Ciencias Económicas, Universidad Nacional del Litoral. Dirección: Moreno 2557, 3.er piso, oficina 3.12 / (CP S3000CVE), Santa Fe, Argentina. Teléfono: 54 (342) 4585610, Int. 169. Correo electrónico: jvigil@ fce.unl.edu.ar.

${ }^{* * *}$ Economista, Universidad Nacional del Litoral, Santa Fe, Argentina. Investigadora del Instituto de Investigación Estado Territorio y Economía de la Facultad de Ciencias Económicas, Universidad Nacional del Litoral. Dirección: Moreno 2557, 3.er piso, oficina 3.12 / (CP S3000CVE), Santa Fe, Argentina. Teléfono: 54 (342) 4585610, Int. 169. Correo electrónico: sacchi_melina@live.com.
} 


\title{
REGIONAL ECONOMIC POLICY, AND SOCIAL IMPACTS: THE CASE OF THE ARGENTINEAN AGRICULTURAL MACHINERY
}

\begin{abstract}
The paper proposes an empirical exploration in Argentina about the way in which an economic region is shaped, the way in which national and regional policies coordinate themselves in that construction, and the relationships that exist between the economic dynamics of the conformed region and its social impacts. Thus, the Argentine region of agricultural machinery (AM) production, located in the heart of the Argentine humid pampa, is analyzed, which "emerged" with greater force in the Argentine political and economic map during a new development model, that tried to carry out a process of reindustrialization of the economy since 2001. This allows to show that the region had a favorable behavior regarding its social indicators.
\end{abstract}

\section{KEYWORDS}

Regional economic development; regional development planning; intergovernmental relations, social impacts; Argentina.

\section{JEL CLASSIFICATION}

O18, R19, R58, H70

\section{CONTENT}

Introduction; 1. Economic policies, institutions and multiple articulations; 2. The measurement of the development and the variables of the social dynamics in the Argentinean AM region; 3. The socioeconomic-demographic dynamics of the Argentinean AM region; 4. Reflections on regional economic development policies; Bibliography.

\section{POLIITICA ECONÔMICA REGIONAL E IMPACTOS SOCIAIS: O CASO DO MAQUI- NÁRIO AGRÍCOLA ARGENTINO}

\section{RESUMO}

O artigo propõe uma exploração empírica na Argentina sobre a formação de uma região econômica, a maneira como políticas nacionais e regionais são articuladas em tal construção, e as relações que existem entre a dinâmica econômica da região formada e seus impactos sociais. Assim, analisa-se a região argentina de produção de maquinário agrícola, localizada no coração do pampa úmido argentino, que "emergiu" com mais força no mapa político e econômico argentino durante o novo modelo de desenvolvimento que buscou um processo de reindustrialização da economia a partir de 2001; isso permite mostrar que a região teve um comportamento favorável em seus indicadores sociais.

\section{PALAVRAS-CHAVE}

Desenvolvimento econômico regional; planejamento do desenvolvimento regional; relações intergovernamentais; impactos sociais. Argentina.

\section{CLASSIFICAÇÃO JEL}

O18, R19, R58, H70

\section{CONTEÚDO}

Introdução; 1. Políticas econômicas, instituições e articulações múltiplas; 2. A medição do desenvolvimento e as variáveis da dinâmica social da região do MA argentino; 3. A dinâmica socioeconômica-demográfica da região do MA argentino; 4. Reflexões sobre as políticas de desenvolvimento econômico regional; Bibliografia. 


\section{INTRODUCCIÓN}

En este trabajo se propone una exploración empírica en Argentina sobre la manera en que se conforma una región económica, el modo como en dicha construcción se articulan políticas nacionales y regionales, y las relaciones que existen entre la dinámica económica de la región conformada y sus impactos sociales. La exploración de esas situaciones en el estudio de caso sirve para debatir aspectos claves de la literatura del desarrollo económico regional.

Buena parte de la literatura del desarrollo económico regional ha planteado la posibilidad de generar desarrollo económico regional a partir de la proximidad, la aglomeración y el enraizamiento local de actores económicos. Sumados a una adecuada infraestructura institucional público-privada local, estos últimos constituyen una fuente importante de competitividad y crecimiento económico, pero sobre todo, de desarrollo; esto indica precisamente que la proximidad favorece la confianza y la reflexividad de las relaciones, reduce los costos de transacción, facilita el derrame de conocimientos y facilita la generación de una oferta de servicios especializados para la comunidad de profesionales y de negocios. Dicho esquema explicativo ha predominado en la interpretación del funcionamiento de las regiones, sobre todo en América Latina desde la década de 1990.

Este trabajo pone en debate esa interpretación del desarrollo económico regional con tres premisas, diferenciadas del enfoque de la proximidad: primero, la aglomeración y el enraizamiento (que suele trabajar con regiones hechas de divisiones jurídico-políticas o demarcaciones basadas en la localización de empresas) muestran la manera en que puede generarse una construcción socioespacial regional en forma relacional a partir de unir redes y vínculos de actores dinámicos con cierta afinidad e intereses más o menos comunes, que atraviesan las divisiones jurídico-políticas. Segundo, la aglomeración y el enraizamiento (que rechaza la injerencia del Estado nacional) muestran que la construcción del espacio regional se configura a partir de las acciones de múltiples niveles de regulación (nacional, regional y local) con gran participación del Estado Nacional; y tercero, la aglomeración y el enraizamiento (que suele focalizar solamente en las dinámicas económicas del desarrollo) muestran un análisis de las dinámicas sociales de una región para evaluar correlaciones con el bienestar de la población en la región conformada.

Con base en estos tres elementos de discusión, se propone un estudio empírico en Argentina en una región estratégica vinculada a la producción de maquinaria agrícola (MA) localizada en el corazón de la pampa húmeda argentina (véase la tabla 1), que emergió con mayor fuerza en el mapa político-económico argentino desde el año 2001; en esa fecha se produjo una gran crisis político-económica y un 
consiguiente cambio del modelo de acumulación hacia un intento de reindustrialización de la economía.

Para el abordaje empírico se trabajó, por un lado, con técnicas cualitativas de recolección de información, a fin de reconstruir el entramado de políticas e instituciones que conforman el espacio regional. Por otro, se seleccionaron indicadores para describir la dinámica socioeconómico-demográfica de la región de MA argentina con base en las estructuras y dinámicas poblacional, de empleo, de las condiciones habitacionales, del sistema educativo y del sistema de salud. Las variables son presentadas en forma evolutiva y comparada, trabajando con datos cuantitativos censales. El trabajo es un estudio exploratorio de correlación (no de causalidad) entre la conformación del espacio económico regional y los impactos sociales de la región conformada. Como resultado, se aportan elementos para comprender la conformación del espacio regional y se sistematiza información sobre las dinámicas sociales de la región conformada, de manera que se hace posible entender en qué sentido ha habido (o no) "desarrollo regional" y quiénes lo han dinamizado.

El trabajo se estructura de la siguiente manera: en la primera sección, se caracteriza la conformación de la región de producción de MA en argentina desde 2001; en la segunda, se describen las variables que constituyen la dinámica sociodemográfica regional; en la tercera, se analizan los resultados; y en la cuarta, se bosquejan proposiciones con base en los resultados obtenidos y se concluye el escrito.

\section{POLÍTICAS ECONÓMICAS Y ARTICULACIONES MÚLTIPLES: LA COMPOSICIÓN ESPACIAL REGIONAL DE LA PRODUCCIÓN DE MA EN ARGENTINA}

Con el objetivo de explorar el proceso de desarrollo ocurrido sobre una región argentina, se propone como preámbulo una reconstrucción de las dinámicas políticas e institucionales que conformaron el espacio regional económico de la producción de MA y la ubicaron con fuerza en el mapa político económico argentino durante el modelo nuevo desarrollista luego de 2001; se muestran en este sentido las redes de conexiones que han atravesado el territorio y la manera en que dichas conexiones caracterizaron la región. Esta descripción permite aproximarse a una comprensión relacional de la región de la MA, compuesta por sus redes institucionales y políticas (antes que por la simple localización de empresas o las divisiones territoriales jurídico-políticas)', al tiempo que hace posible identificar el rol de los diferentes

\footnotetext{
1 Para un análisis del enfoque relacional ver Allen y Cochrane (2007), Allen, Massey y Cochrane (1998), Amin, (2004 y 2008); comparar con MacLeod y Jones (2007). Para un abordaje del debate más vernáculo del tema ver Vigil (2013) y Riffo (2008). Una rediscusión más reciente del regionalismo y el debate relacional puede verse en Jones (2016), Paasi y Metzger (2017, Pike, Rodríguez-Pose y Tomaney (2016).
} 
ámbitos de regulación (nacional, provincial y local) y caracterizar el tipo de política aplicada (véase resumen de dinámica institucional en la tabla 1).

\section{Tabla 1. Resumen de la dinámica institucional MA}

\begin{tabular}{|c|c|c|c|c|}
\hline \multicolumn{2}{|r|}{ Instituciones } & Objetivo / actividad & Localidades comprendidas & Año \\
\hline \multirow{6}{*}{ 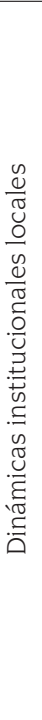 } & Informe de Unido & $\begin{array}{l}\text { Necesidad de instituciones de } \\
\text { apoyo técnico a las pymes }\end{array}$ & $\begin{array}{l}\text { Armstrong, Las Parejas, Suncha- } \\
\text { les, El Trébol, San Vicente, Casilda, } \\
\text { Firmat, Fuentes, Arequito, Marcos } \\
\text { Juárez, Bell Ville, Las Varillas, San } \\
\text { Francisco, Pergamino. }\end{array}$ & 1980 \\
\hline & Oficinas DAT & $\begin{array}{l}\text { Fondos gobierno central y fondos } \\
\text { de la Agencia Española de Coope- } \\
\text { ración Internacional }\end{array}$ & Las Parejas & 1992 \\
\hline & Maquinagros & $\begin{array}{l}\text { Asociación de pymes para mejorar } \\
\text { la inserción externa }\end{array}$ & Las Parejas & \\
\hline & Cideter & $\begin{array}{l}\text { Fundación empresarial de apo- } \\
\text { yo a pymes }\end{array}$ & Las Parejas, Armstrong, Las Rosas & 2000 \\
\hline & Modemaq & $\begin{array}{l}\text { Movimiento para la Defensa de la } \\
\text { Maquinaria Agrícola (sindical em- } \\
\text { presaria) }\end{array}$ & & \\
\hline & CFI & Clúster industrial de MA & $\begin{array}{l}\text { Armstrong, Las Rosas, Tortugas, } \\
\text { Marcos Juárez, Arequito, Bustin- } \\
\text { za, Fuentes, Firmat, San José, Cruz } \\
\text { Alta, Arteaga; C. Uruguay. }\end{array}$ & 2002 \\
\hline \multirow{7}{*}{ 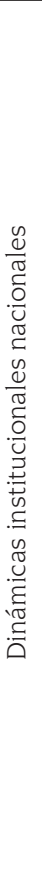 } & $\begin{array}{l}\text { Ministerio de } \\
\text { Economía de la } \\
\text { Nación }\end{array}$ & $\begin{array}{l}\text { Foro Nacional de Competitivi- } \\
\text { dad MA } \\
\text { CONSur programa de exportación } \\
\text { PROASO: proyecto asociativo }\end{array}$ & Santa Fe, Córdoba, Buenos Aires & 2004 \\
\hline & $\begin{array}{l}\text { Ministerio } \\
\text { de Ciencia, } \\
\text { Tecnología } \\
\text { y BID }\end{array}$ & $\begin{array}{l}\text { Fondo de Investigación Científica } \\
\text { Fondo Tecnológico Argentino } \\
\text { Cecma (Clúster Empresarial) }\end{array}$ & Santa Fe, Córdoba, Buenos Aires & $2005 / 6$ \\
\hline & $\begin{array}{l}\text { Ministerio de } \\
\text { Relaciones } \\
\text { Exteriores }\end{array}$ & $\begin{array}{l}\text { Agro Showroom } \\
\text { Muestra Nacional Pyme Industrial } \\
\text { Programa de Promoción Sectorial }\end{array}$ & $\begin{array}{l}\text { Las Parejas, Armstrong y Mar- } \\
\text { cos Juárez }\end{array}$ & 2005 \\
\hline & $\begin{array}{l}\text { Ministerio de } \\
\text { Agricultura (INTA) }\end{array}$ & $\begin{array}{l}\text { Incentivo a exportaciones de MA } \\
\text { Informes coyuntura demanda } \\
\text { de MA } \\
\text { PRECOP II: oferta y demanda de MA }\end{array}$ & $\begin{array}{l}\text { Las Parejas, Armstrong, Marcos } \\
\text { Juárez y Las Rosas }\end{array}$ & $\begin{array}{c}2003- \\
2009\end{array}$ \\
\hline & $\begin{array}{l}\text { Instituto Nacional } \\
\text { de Tecnología } \\
\text { Industrial (INTI) }\end{array}$ & $\begin{array}{l}\text { Acuerdos bilaterales de expor- } \\
\text { tación }\end{array}$ & Santa Fe, Córdoba, Buenos Aires & $\begin{array}{c}2005 y \\
2011\end{array}$ \\
\hline & AProMeCAS & $\begin{array}{l}\text { Centro de Transferencia de Resul- } \\
\text { tados, aglomerado metalmecánico } \\
\text { santafecino }\end{array}$ & Las Parejas & 2007 \\
\hline & $\begin{array}{l}\text { Ministerio de } \\
\text { Producción }\end{array}$ & $\begin{array}{l}\text { Programas Recuperación Produc- } \\
\text { tiva (Re Pro) }\end{array}$ & Santa Fe, Córdoba, Buenos Aires & $2007 / 8$ \\
\hline
\end{tabular}




\begin{tabular}{|c|c|c|c|c|}
\hline \multicolumn{2}{|r|}{ Instituciones } & Objetivo / actividad & Localidades comprendidas & Año \\
\hline 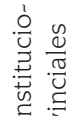 & Santa Fe & $\begin{array}{l}\text { Cadena de Valor de la Maquina- } \\
\text { ria Agrícola }\end{array}$ & Santa Fe & 2008 \\
\hline 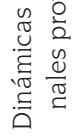 & Buenos Aires & $\begin{array}{l}\text { Financiamiento del distrito indus- } \\
\text { trial MA } \\
\text { Financiamiento del grupo asocia- } \\
\text { tivo GAPMA }\end{array}$ & $\begin{array}{l}\text { Chivilcoy, Carlos Casares y } 9 \text { de } \\
\text { Julio }\end{array}$ & $2005 / 6$ \\
\hline
\end{tabular}

Fuente: elaboración propia.

\subsection{Dinámicas institucionales locales vinculadas a la MA}

Un punto de partida de la construcción regional (entre otros posibles) y su asentamiento se encuentra en el comportamiento que tuvo inicialmente la dinámica institucional de apoyo al sector de la producción de MA. En los inicios de la década de 1990, el gobierno de la provincia de Santa Fe (Argentina) creó unas dependencias de apoyo técnico a las pequeñas y medianas empresas (pymes) en algunas localidades, que recibieron el nombre de Direcciones de Asesoramiento y Servicio Tecnológico $(\mathrm{DAT})^{2}$. La idea de contar con dependencias de este tipo ya había sido propuesta para el caso de la MA en la década de 1980, como sugerencia de un informe solicitado por el gobierno de Santa Fe a la Organización de las Naciones Unidas para el Desarrollo Industrial - Unido (véase Gasparetto, 1981): en ese documento se indicaba que dichas instituciones de apoyo facilitarían una mejora en la etapa de diseño de las empresas, la adopción de normas de calidad y el acceso a información relevante del sector (p. ej. ferias, eventos, vinculación universitaria, I+D, transferencia, etc.).

Una de esas DAT se estableció en 1992, en la localidad de Las Parejas en Santa Fe (tabla 1), donde ya existía un pequeño asentamiento de firmas vinculadas a la $\mathrm{MA}^{3}$. Esa oficina adquirió una gran capacidad de captar financiamiento para ese sector: por ejemplo, recibió fondos del gobierno central para estimular desarrollos tecnológicos de pymes de MA; recibió fondos de la Agencia Española de Cooperación Internacional para promover una mejora en los procesos de producción en las pymes de MA; y gestionó fondos del gobierno central para ayudar a un grupo de empresas locales a conformar lo que se denominó Maquinagros (una asociación de pymes con intenciones de mejorar la inserción a los mercados externos). Una vez consolidada, hacia finales de la década de 1990 la oficina de la DAT pasó de ser una dependencia gubernamental a convertirse en una oficina público-pri-

2 En la página web de la Direcciones de Asesoramiento y servicio Tecnológico (DAT) se pueden consultar los diferentes servicios que ofrece esta entidad a los empresarios de la región de Santa Fe.

3 En Bil (2009) se pueden consultar los inicios de la industria de MA Argentina. 
vada; y conformó, junto a algunas empresas, una fundación empresarial (Cideter) ${ }^{4}$ que continuaría su labor 5 .

Iniciada la década del 2000, la red de localidades vinculadas a la MA se hizo más explícita y se amplió el espacio regional: por ejemplo, en 2002, el denominado Consejo Federal de Inversiones (CFI), una institución federal para promocionar el desarrollo regional ${ }^{6}$, financió una investigación sobre la MA: según Castellarín, Moro, y Bianchi (2003), los resultados de la misma indicaban que existía una zona (algo difusa) en el sur de la provincia de Santa Fe con pymes especializadas en la producción de MA, a la cual se le dio el nombre de Clúster Industrial Las Parejas. Dicho trabajo indicaba también que otras localidades como Armstrong, Las Rosas, Tortugas, Marcos Juárez, Arequito, Bustinza, Fuentes, Firmat, San José de la Esquina, Cruz Alta, Arteaga, entre otras, estaban vinculadas a Las Parejas por la activa participación que sus respectivos centros industriales estaban teniendo entre sí a través de un foro denominado Modemaq (Movimiento para la Defensa de la Maquinaria Agrícola), que había emergido para expresar las demandas y objetivos políticos del sector. Así entonces, el informe hacía explicitas esas relaciones entre localidades productoras de MA.

\subsection{Crisis político-económica y apoyo nacional a la producción de MA}

Luego de la crisis político-económica de Argentina en 2001, se inició un nuevo modelo de desarrollo macroeconómico que economistas como Varesi (2010) llamaron nuevo desarrollismo (como intento de reivindicación moderna del período de sustitución de importaciones de décadas pasadas). Este se caracterizó por la aplicación de un paquete relativamente heterodoxo que incluyó una política monetaria expansiva con cierto equilibrio fiscal; un tipo de cambio más alto (por devaluación) que redefinió la relación interna/externa del sector industrial; y una tendencia (aun con dificultades) hacia un ensayo de reindustrialización de la economía por sustitución de importaciones, con intentos de valorizar al sector productivo sobre el financiero, con incentivos a la reutilización de la capacidad ociosa, mayor estímulo a la demanda doméstica y recomposición del poder de compra de la población (al menos hasta el 2013), lo cual incluía subsidios a servicios básicos y una fuerte intervención social universal inclusiva hacia los sectores más vulnerables. En lo referido a la política sectorial, se intentó revertir la situación del sector metalmecánica/MA,

\footnotetext{
4 Resolución n. 019 IGPJ, Santa Fe (07/01/2000).

5 CIDETER se convirtió Unidad de Vinculación Tecnológica (ver Ley 23.877/1990) para dar soporte a empresas en proyectos tecnológicos.

6 Se pueden consultar los detalles de este proceso en las páginas web del CIDETER y el Consejo Federal de Inversiones (CFI).
} 
que hasta el momento había sido sitiado por problemas en su balanza comercial (Albornoz, Anlló y Bisang, 2010); la dificultad para lograr articulación de políticas y programas sectorial-regional; y la imposibilidad de revertir el proceso de concentración y creciente transnacionalización del capital vinculado al sector (véanse Hybel, 2006 y Romero, 2010), entre otros problemas.

En ese contexto, a las dinámicas y articulaciones institucionales iniciales que iban delimitando el espacio territorial alrededor de la zona sur oeste de la provincia de Santa Fe se sumó una serie de políticas y dinámicas macroeconómicas que dieron lugar a un reposicionamiento de la región de la MA, ahora en el centro del "escenario económico nacional", y generaron una reconfiguración de su morfología espacial. En primer lugar, se abrió aún más el espacio regional a una gran variedad de actores con interés en la producción de MA, que se hizo notorio desde que se impulsó (a través del Ministerio de Economía de la Nación) el Foro Nacional de Competitividad de la MA. Su objetivo era desarrollar estrategias de acción conjunta que incluirían aspectos como la ampliación de la participación de la producción nacional en la demanda interna; la mejora de las capacidades tecnológicas de las firmas; el aumento de la incorporación de valor agregado a los productos; el fortalecimiento de la vinculación de las firmas con las instituciones tecnológicas; y la mejora de la inserción externa, como se planteó en el Foro Nacional de Competitividad de la Maquinaria Agrícola de 2005. El Foro actuó como la primera articulación formal de instituciones de diferentes niveles: gobierno nacional, gobiernos provinciales de Santa Fe, Córdoba y Buenos Aires, municipios, organismos descentralizados, cámaras empresariales, sindicatos y una gran cantidad de empresas. Desde entonces, ya no había un espacio reducido a un grupo de firmas e instituciones locales; en lugar de ello, se configuraba un lugar de preocupación y ocupación nacional.

En segundo lugar, y en línea con los objetivos del Foro, el Estado nacional, a través de la Agencia Nacional de Promoción Científica y Tecnológica (ANPCyT) del Ministerio de Ciencia, Tecnología e Innovación Productiva, actuó fomentando las áreas de investigación y desarrollo vinculadas al sector metalmecánica/MA: se financiaron, por un lado, proyectos de investigación a través del Fondo para la Investigación Científica y Tecnológica (FONCyT); y por otro, se generaron líneas de crédito y subsidios a empresas individuales o aglomeradas de la MA a través del Fondo Tecnológico Argentino (Fontar). De este último surgió el programa "Promoción de clusters industriales y redes productivas" que dio paso al denominado Clúster Empresarial Cideter de la Maquinaria Agrícola ${ }^{7}$, aplicado en las localidades de Las Parejas, Armstrong, Las Rosas y Marcos Juárez (Cecma, 2006), aunque incluía

7 El proyecto NA 002/06 (Res. ANPCyT 27/12/2006) es una formalización de la idea expresada en el informe financiado por el CFI (véase la nota 6). 
otras localidades cercanas dentro de un radio de $150 \mathrm{~km}$, y que también permitió la creación de una institución local (continuadora de la DAT y de Cideter), denominada Cecma (Clúster Empresarial Cideter de la Maquinaria Agrícola), encargada de llevar adelante los objetivos y monitorear los resultados del programa. Lo interesante de Cecma es que volvió a incluir más instituciones y localidades vinculadas a la MA, al generar una Mesa de Articulación que dio participación a gobiernos provinciales (Santa Fe, Córdoba), municipios (Armstrong, Las Parejas, Marcos Juárez, Las Rosas) y sus cámaras empresariales/industriales, asociaciones empresariales nacionales del sector (p. ej. Cámara Argentina de Fabricantes de Maquinaria Agrícola, Asociación de Industriales Metalúrgicos de la República Argentina), institutos autárquicos y autónomos de investigación y desarrollo (p. ej. Instituto Nacional de Tecnología Industrial, Instituto Nacional de Tecnología Agropecuaria), universidades (ej. Universidad Nacional de Rosario, Universidad Nacional del Litoral) y empresas locales, conformándose con ello una gran red institucional y productiva. Más recientemente, con eje en la localidad de Las Parejas, se financió desde el Estado nacional, y con apoyo del Banco Interamericano de Desarrollo, otro aglomerado industrial, denominado Aglomerado Metalmecánico del Cordón Agroindustrial Santafesino (AProMeCAS) ${ }^{8}$.

En tercer lugar, el Estado nacional trabajó en la promoción de la oferta exportable de producción doméstica de MA. Por ejemplo, desde 2003, a través del Ministerio de Industrias, se financiaron proyectos asociativos entre empresas: ejemplo de ello es un Consorcio de Exportación (Con-Sur) con eje en Las Parejas, que sirviera para impulsar a otras empresas a externalizar su producción. Se financió también un "proyecto asociativo" denominado PRO-ASO, de 11 empresas de Armstrong y Las Parejas, con el objetivo de desarrollar una cosechadora de tipo "axial" con un $85 \%$ de componentes nacionales (aunque no tuvo resultados concretos visibles).

En la misma línea se financió, con apoyo del Ministerio de Relaciones Exteriores, una feria inversa de exportaciones denominada Agro Showroom?', con epicentro en Las Parejas, Armstrong y Marcos Juárez, tendiente a dar a conocer las potencialidades de la MA argentina (Cideter, 2009), que posteriormente se volvió a realizar con el nombre de Muestra Nacional de la Pyme Agroindustrial. A su vez, a través del Ministerio de Agricultura, el Estado nacional generó reportes sobre el estado de situación de la oferta local y demanda global de MA, indicando los posibles nichos de exportación para la producción doméstica ${ }^{10}$. Otro organismo estatal, el Ministe-

\footnotetext{
8 Proyecto BID 2923/OC-AR (PAC II).

9 Proyecto PNUD ARG/05/024.

${ }^{10}$ Véanse el Proyecto PRECOP II (www.cosechaypostcosecha.org) y el Programa Nacional de Valor Agregado (INTA).
} 
rio de Relaciones Exteriores y Culto, gestionó el Programa de Promoción Sectorial (PPS) para incrementar y diversificar las exportaciones argentinas. Para el caso de la MA, se detallaron los perfiles de mercados potenciales (p. ej. Rusia, Sudáfrica, Australia, Brasil, etc.) con información sobre la logística de la exportación (secuencias, documentos necesarios, distribuidores, organismos útiles, etc.), y se prestó asistencia técnica para avanzar en la penetración de dichos mercados.

A su vez, además de "fomentar" la oferta exportable, el Estado nacional avanzó en la generación de mercados concretos para la MA: gestionó, a través del Instituto Nacional de Tecnología Industrial (INTI), acuerdos bilaterales de exportación con el gobierno venezolano, como lo indican Solanas, Campisi y Risso (2009). Como dato, para 2006, y con un incremento del 81\% de las exportaciones en MA argentina, Venezuela representaba hasta casi el $60 \%$ del destino de todas las exportaciones según Bragachini (2014), lo que marcaba la importancia del acuerdo" ${ }^{11}$.

La promoción de las exportaciones de MA iba en línea con un intento de aprovechamiento del precio de los commodities en los mercados internacionales, aspecto que constituía una "ventana de oportunidad" que contribuía a sostener la demanda de MA a través de sus efectos en la rentabilidad del productor agrícola (véanse Vigil y Magri, 2015). En Argentina, este había sido un aspecto importante tenido en cuenta por el gobierno de turno para impulsar la venta de producción doméstica, a tal punto que se ha indicado incluso que existió un paralelismo perfecto entre los precios en el agro y las ventas del sector de MA (Bragachini, 2008, p. 2).

\subsection{Dinámicas institucionales provinciales para la MA}

En cuarto lugar, en esta reconfiguración de la morfología espacial de la región, el Estado provincial de Santa Fe aportó a la consolidación de ese espacio económico alrededor de la producción de MA cuando adoptó la idea de "Cadena de Valor de la Maquinaria Agrícola y Componentes Relacionados" (Gobierno de Santa Fe, 2008, p. 9) para definir y ordenar sus herramientas de política industrial en su ámbito de influencia. Aunque con diferencias de políticas partidarias con el gobierno nacional, el Estado provincial coincidía con los objetivos del Foro de MA y sugería:

- Reconsiderar, junto con el gobierno nacional, las políticas macroeconómicas para el sector (tipo de cambio, medidas proteccionistas, aumentar las herramientas impositivas para los productos importados, etc.)

- Reducir la presión impositiva.

${ }^{11}$ En materia de políticas sectoriales para MA, véanse Goldstein y Lavarello (2011). Véase también el informe Sabel et al. (2006) sobre MA argentina y la necesidad de fortalecer el INTI e INTA. 
- Mejorar la competitividad tecnológica internacional de las empresas (fuerza de trabajo, escala de producción, practicas asociativas, estándares de calidad, etc.).

- Desarrollar soporte institucional local para las empresas.

- Desarrollar herramientas financieras adecuadas para productores y compradores de MA.

Así, aunque no había elementos claros sobre las implicancias espaciales de la adopción del concepto de cadena de valor, el Estado provincial logró abrir aún más la dinámica de la producción de MA incorporando nuevos actores organizacionales a un polo decisional provincial (p. ej. gobierno Santa Fe, Instituto Nacional de Tecnología Industrial, Instituto Nacional de Tecnología Agropecuaria, Fundación CIDETER, Universidades Nacionales, DAT, IRAM y Centros Industriales, Cancillería, Ministerio de Industria de la Nación, etc.).

En quinto lugar, en línea con el Estado nacional, el Estado provincial de Buenos Aires adoptó un Programa de financiamiento para Distritos Productivos y conformó para 2005-2006 un "distrito industrial de MA" en las localidades de Chivilcoy, Carlos Casares y 9 de Julio, compuesto por 18 empresas: 8 terminales y 10 de agropartes (Ciecti, 2013). La propuesta estaba destinada a mejorar la competitividad de las pymes, aunque las actividades concretas del Estado sobre los distritos han sido escasas y difusas. En la misma línea se financió a un grupo asociativo denominado Gapma (Grupo Asociativo de Productores de Maquinaria Agrícola), en la misma zona del norte de Buenos Aires ${ }^{12}$ (véanse Piñero, Herrera y Di Meglio, 2011), con la intención de promocionar la oferta exportable de las pymes.

Por el tipo de políticas desplegadas, sus destinatarios, los actores institucionales participantes y la localización de las empresas vinculadas a la producción de maquinaria agrícola, se sintetiza un "mapeo" de la producción de MA en gráfico 1.

En esa macrorregión, entendida como una conformación espacial en la que existen patrones económicos y preocupaciones productivas comunes, receptora de políticas "regionalistas" y con un nivel importante de desarrollo institucional desde múltiples niveles de regulación de apoyo a las pymes (este conjunto de elementos la diferencia de otro tipo de conformación espacial), se fue destacando la presencia de empresas productoras de sembradoras, pulverizadoras e implementos agrícolas (agropartes), por un lado; y cosechadoras y tractores, por otro. Estos dos últimos subgrupos son más complejos, con menor cantidad de empresas locales y amplio

\footnotetext{
${ }^{12}$ Con las siguientes localidades: Colón, 9 de Julio, Chivilcoy, Tandil, Olavarría, Carlos Casares, Lincoln, Carmen de Areco, y San Nicolás.
} 


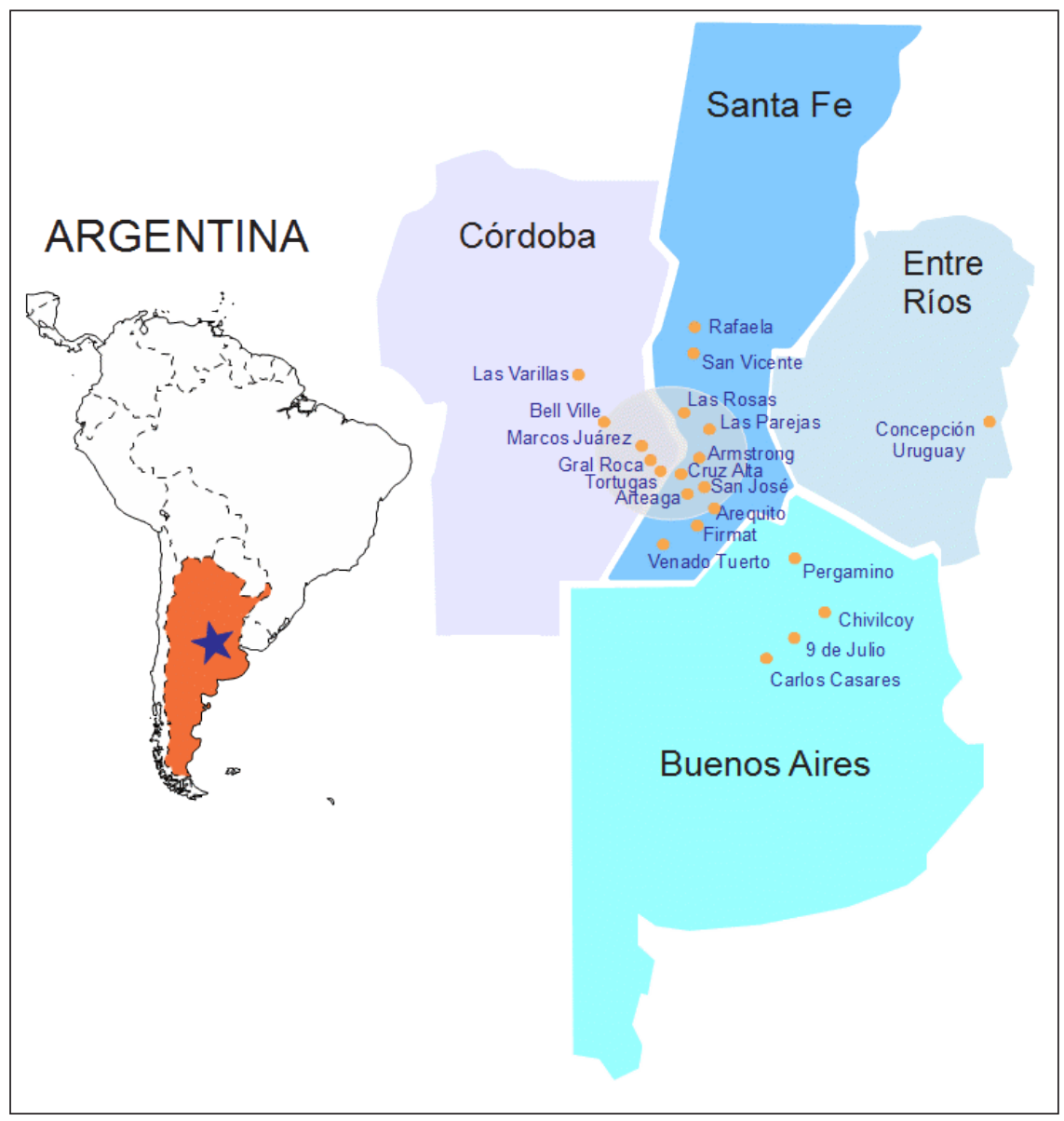

Fuente: elaboración propia con la información recolectada para describir la dinámica institucional (tabla 1).

dominio de las extranjeras (Hybel, 2006). Según Albornoz, Anlló y Bisag (2010), la producción doméstica de MA llegó a representar en 2007 un valor bruto de producción (VBP) de USD 844,6 millones ${ }^{13}$ (21\% de los bienes de capital), subsector que contiene unas 3.800 firmas, las cuales generan USD 4.200 millones anuales (datos 2007). Abarcando a los bienes de capital, el sector de metalmecánica contiene unos 23.000 establecimientos y un VBP anual cercano a los USD 22.000 millones, lo que implica una participación del 13\% en el PBI (datos para 2008) (Albornoz, Anlló y Bisang, 2010). En términos de tamaño de empresas, los análisis indicarían que

13 Adimra sostiene que el valor agregado bruto de la producción local ascendía a cerca de 1000 millones de dólares en 2007; y Cafma sostiene que fue de 850 millones en ese año (Albornoz, Anlló y Bisang, 2010). 
podrían existir tres grupos: uno de una veintena de empresas cuyos niveles de empleo superan los 100 ocupados promedio, que representaría alrededor del $40 \%$ de la facturación total; otro de unas 80 empresas de entre 25 y 100 empleados, cuya facturación conjunta representaría un 25\% del mercado; y otro más de un centenar de empresas de menos de 25 empleados, que representan cerca del 35\% de la facturación restante (Albornoz, Anlló y Bisang, 2010).

\section{LA MEDICIÓN DEL DESARROLLO Y LAS VARIABLES PARA DESCRIBIR LA DINÁMICA "SOCIAL" DE LA REGIÓN DE LA MAQUINARIA AGRÍCOLA ARGENTINA}

En esa aproximación a la espacialidad de la dinámica económica de la región de la producción de MA en Argentina, al describir las principales localidades que han quedado incluidas en dicha región, y con una gran cantidad de políticas, programas y herramientas financieras vinculadas para potenciar procesos de desarrollo, surge la pregunta sobre cuál ha sido el desempeño de las variables socioeconómicas de las localidades vinculadas a esas políticas de regeneración económica. Para avanzar en esos objetivos, este trabajo propone un recorrido exploratorio (evolutivo y comparado) por algunas variables que son determinantes de la dinámica "social" de una región.

No existe consenso en el debate sobre cómo se mide el desarrollo — regional— (Widuto, 2016), ni tampoco sobre la selección de los indicadores más adecuados para "territorializar" o representar en el espacio la materialización del desarrollo (ej. regiones, países... desarrollados, subdesarrollados, etc.). La discusión de estos aspectos ha evolucionado desde los enfoques más "tradicionales", que tomaban elementos puramente económicos (p. ej. PBI, PBI per cápita, densidad económica, etc.) y que aún se utilizan en la Unión Europea (p. ej. Cohesion Policy Funding 2014-2020) para determinar la distribución de fondos y las categorías de regiones (más o menos desarrolladas) (véanse Sánchez y Ruiz, 2013; Vandermotten, Peeters y Lennert, 2011), hacia aquellos con indicadores denominados "sociales", según los cuales las variables puras del crecimiento económico dicen poco sobre inequidades sociales y territoriales. Entre estos últimos se destaca el denominado índice de desarrollo humano (IDH), un indicador sintético de los logros medios obtenidos en dimensiones consideradas fundamentales del desarrollo humano: entre ellas se incluyen, además de factores económicos, la educación y salud, como los vinculados a medir la posibilidad de tener una vida larga y saludable (esperanza de vida), de adquirir conocimientos (escolaridad) y de disfrutar de un nivel de vida digno (necesidades básicas). Trasladado a recortes territoriales (ej. ciudades, regiones) el IDH dio paso a los indicadores de desarrollo humano territorial - IDHT (véase un ejemplo en Pol, 2011). 
Otro indicador "social" de relevancia emergió luego de la conferencia Beyond GDP a partir del reporte de Stiglitz, Sen y Fitoussi (2009), que introducía una perspectiva longitudinal en la medición del desarrollo; es decir, medía las condiciones actuales, así como su posibilidad de mantenerse en el tiempo. Lo anterior configuró un interesante debate, que continuó incluso en 2013 (véanse Fleurbaey y Blanchet, 2013). Ingresaron mientras tanto a la discusión las consideraciones sobre indicadores medioambientales como síntomas del desarrollo (ej. huella ecológica, emisiones contaminantes, etc.), desde que se asumió que el crecimiento económico traía aparejados costos medioambientales considerables. Luego, también se incorporaron perspectivas sobre los indicadores del desarrollo tecnológico (p. ej. telefonía móvil, uso redes sociales, etc.) como nuevas herramientas novedosas para marcar en qué medida avanza el confort social. Más recientemente, desde 2014, ha aparecido el denominado índice de progreso social (SPI), que se (auto) propone superador de los anteriores, sobre todo del IDH ${ }^{14}$, impulsado por uno de los economistas más influyentes del mainstream regionalista (Michael Porter), y que sugiere evitar la medición de aspectos económicos tradicionales en cualquiera de los algoritmos de los indicadores sociales.

Lo cierto es que no existe un consenso generalizado entre académicos y políticos del desarrollo sobre qué medir o cuándo hacerlo (después de la aplicación de la política). A escala regional, la falta de consenso es similar. Las instituciones financieras, académicas y públicas suelen pregonar diferentes metodologías: por ejemplo, el Regional Competitiveness Index, que incluye medición de infraestructura institucional, capital humano, etc.; el Regional Innovation Scoreboard, que incluye variables para educación, gasto en I+D, solicitudes de patentes, exportaciones de bienes intensivos en conocimientos, etc.; y el Regional Human Development Index, entre muchos otros que reproducen el debate anterior. Pero además de este debate más conceptual, a escala regional, la situación de la medición del desarrollo se complejiza por la ausencia de datos fiables, históricos, comparables y periódicamente producidos, y por la falta de instituciones que los generen.

La situación de la medición del desarrollo muchas veces suele resolverse más pragmáticamente a partir de la utilización de datos posibles y existentes. Para el caso de la región de la producción de la MA bajo estudio, la situación se complejiza aún más (además del debate conceptual y la falta de instituciones que generen datos), pues se propuso un "recorte" regional a medida, hecho de redes de relaciones de actores (económicos e institucionales) y de políticas. Es una construcción social

${ }^{14}$ Todos los detalles del índice de progreso social se pueden consultar en: Social Progress Index. 
dinámica en un tiempo determinado, y no un mero recorte estático de jurisdicciones jurídico-políticas fijas (que suelen tener instituciones generadoras de datos).

Dicho esto, se resolvió trabajar con datos cuantitativos secundarios relevados por censos (Censo Nacional de Población y Vivienda 1991, Censos Nacionales de Población Hogares y Viviendas 2001 y 2010), con información por localidad y por provincia. No fue posible obtener la información de encuestas que se relevan todos los años, como sería el caso de la Encuesta Permanente de Hogares (EPH) en Argentina, debido a que las localidades pertenecientes a la región de la MA no se encuentran en los grandes aglomerados urbanos. Y la EPH continua, que se realiza también al interior de las provincias, tiene como limitante para este trabajo que la muestra no es representativa para la localidad. Así entonces, las fechas de realización de los censos y la información disponible limitaron y delimitaron los indicadores a utilizar, así como sus periodos de comparación. Junto a estas limitantes apareció la imposibilidad de conseguir la información disponible por el Censo de 1991 para las localidades pertenecientes a las provincias de Córdoba y Buenos Aires, por no estar publicados los resultados para dicho nivel de desagregación. Los datos de las localidades pertenecientes a la provincia de Santa Fe se obtuvieron por la digitalización y publicación hecha por el IPEC de esta provincia.

Ahora bien, asumiendo estas lagunas y dificultades se propone describir y analizar la dinámica socioeconómico-demográfica de la región, lo cual incluye elementos como la estructura y dinámica poblacional (crecimiento de la población) de la población económicamente activa y su condición (tasa de actividad, empleo y desocupación); del nivel de vida (necesidades básicas insatisfechas), de indicadores de educación (tasa de analfabetismo y nivel de instrucción de la población) y de indicadores de salud (agua potable y saneamiento básico y nivel de cobertura de obra social). Se propuso un análisis diacrónico de los indicadores por localidades involucradas en la región de la MA, de manera que permitan visualizar evoluciones en el tiempo (dinámica). A su vez, se propuso comparar los indicadores de las localidades de la región de la MA con los de las localidades que no estuvieron directamente vinculadas con la producción de MA (por provincia), que en principio no han sido alcanzadas por las políticas de regeneración económica regional en sentido estricto, y que metodológicamente actúan como una especie de grupo de control. También se utilizan las medias provinciales como mecanismo de comparación.

El diagnóstico de esta exploración debería alertar sobre algún patrón diferencial de indicadores sociales en estas localidades que recibieron políticas regionalistas específicas de regeneración económica. Con ello se obtendría un panorama general del comportamiento socioeconómico y demográfico de la región de la produc- 
ción de MA, y se establecerían comparaciones y correlaciones con otras regiones y con los indicadores de los niveles departamentales, provinciales y nacionales en las variables propuestas. Se pretende contribuir a comprender si es posible que exista una relación entre el crecimiento económico de la producción de MA (y el caudal de políticas, programas, instituciones movilizadas y recursos económicos utilizados) y una mejora en las condiciones de bienestar de la población de la región.

\section{LA DINÁMICA SOCIOECONÓMICO-DEMOGRÁFICA DE LA REGIÓN DE LA MA ARGENTINA EN LA ETAPA NUEVO DESARROLLISTA}

En principio, y como adelanto general, el análisis realizado muestra que las localidades vinculadas a la producción de MA que conformaron la región de producción de MA, y que fueron objeto de políticas de regeneración económica regional durante la década del 2000, tuvieron un comportamiento socioeconómico-demográfico distintivo (la tabla 2 resume las variables en su comportamiento diacrónico y comparado; en el anexo se muestran los datos cuantitativos).

Tabla 2. Dinámica social de la región de la producción de MA Argentina

\begin{tabular}{|c|c|c|c|}
\hline Dimensión & Indicador & $\begin{array}{c}\text { Comportamiento } \\
\text { diacrónico de la región } \\
\text { de la MA }\end{array}$ & Comportamiento Comparado de la región de la MA \\
\hline $\begin{array}{l}\text { Dinámica } \\
\text { poblacio- } \\
\text { nal }\end{array}$ & Población & $\begin{array}{l}\text { Crece entre } 2001 \text { y } \\
2010\end{array}$ & $\begin{array}{l}\text { En mayor medida que las medias provinciales } \\
\text { Similar a la media del resto de localidades }\end{array}$ \\
\hline \multirow{3}{*}{ PEA } & Actividad & $\begin{array}{l}\text { Crece entre } 2001 \text { y } \\
2010\end{array}$ & $\begin{array}{l}\text { En mayor medida que las medias provinciales } \\
\text { En mayor medida que el resto de localidades (valor } \\
\text { absoluto) } \\
\text { En mayor medida que el resto de localidades } \\
\text { (variación intercensal) }\end{array}$ \\
\hline & Empleo & $\begin{array}{l}\text { Mejora entre } 2001 \text { y } \\
2010\end{array}$ & $\begin{array}{l}\text { Mejor que las medias provinciales } \\
\text { Mejor que el resto de localidades (valor absoluto) } \\
\text { Mejor que el resto de localidades (variación } \\
\text { intercensal) }\end{array}$ \\
\hline & Desocupación & $\begin{array}{l}\text { Mejora entre } 2001 \text { y } \\
2010\end{array}$ & $\begin{array}{l}\text { Mejor que las medias provinciales } \\
\text { Mejor que el resto de localidades de Santa Fe y } \\
\text { Buenos Aires. } \\
\text { Peor para las localidades de la provincia de Córdoba } \\
\text { (valor absoluto) } \\
\text { Mejor que el resto de localidades de Santa Fe y } \\
\text { Córdoba. } \\
\text { Peor para las localidades de la provincia de Buenos } \\
\text { Aires (variación intercensal) }\end{array}$ \\
\hline
\end{tabular}


Políica económica regional e impactos sociales: el caso de la maquinaria agrícola argentina

\begin{tabular}{|c|c|c|c|}
\hline Dimensión & Indicador & $\begin{array}{l}\text { Comportamiento } \\
\text { diacrónico de la región } \\
\text { de la MA }\end{array}$ & Comportamiento Comparado de la región de la MA \\
\hline $\begin{array}{l}\text { Condicio - } \\
\text { nes de vida }\end{array}$ & Hogares con NBI & $\begin{array}{l}\text { Mejora entre } 2001 \text { y } \\
2010\end{array}$ & $\begin{array}{l}\text { Mejor que las medias provinciales } \\
\text { Mejor que el resto de localidades (valor absoluto) } \\
\text { Mejor que el resto de localidades de Santa Fe y } \\
\text { Córdoba. } \\
\text { Peor para las localidades de Buenos Aires (variación } \\
\text { intercensal) }\end{array}$ \\
\hline & Analfabetismo & $\begin{array}{l}\text { Mejora entre } 2001 \text { y } \\
2010\end{array}$ & $\begin{array}{l}\text { Mejor que las medias provinciales } \\
\text { Mejor que el resto de localidades (valor absoluto) } \\
\text { Peor que el resto de localidades (variación intercensal) }\end{array}$ \\
\hline Educación & $\begin{array}{l}\text { Nivel de instruc- } \\
\text { ción }\end{array}$ & $\begin{array}{l}\text { Mayoría de localida- } \\
\text { des mejora entre } 2001 \\
\text { y } 2010\end{array}$ & $\begin{array}{l}\text { Mejor que las medias provinciales } \\
\text { Mejor que el resto de localidades (valor absoluto) } \\
\text { Peor que el resto de localidades de Santa Fe y } \\
\text { Buenos Aires. } \\
\text { Mejor que el resto de las localidades de Córdoba } \\
\text { (variación intercensal) }\end{array}$ \\
\hline \multirow[t]{2}{*}{ Salud } & $\begin{array}{l}\text { Agua potable y } \\
\text { Saneamiento bá- } \\
\text { sico }\end{array}$ & $\begin{array}{l}\text { Mejora entre } 2001 \text { y } \\
2010\end{array}$ & $\begin{array}{l}\text { Comportamiento heterogéneo con respecto a las } \\
\text { medias provinciales } \\
\text { Mejor que el resto de localidades (valor absoluto) } \\
\text { Peor que el resto de localidades para Córdoba y } \\
\text { Buenos Aires. } \\
\text { Mejor que el resto de las localidades para Santa Fe } \\
\text { (variación intercensal) }\end{array}$ \\
\hline & Cobertura salud & $\begin{array}{l}\text { Mejora entre } 2001 \text { y } \\
2010\end{array}$ & $\begin{array}{l}\text { Mejor que las medias provinciales } \\
\text { Mejor que el resto de localidades (valor absoluto) } \\
\text { Mejor que el resto de localidades (variación } \\
\text { intercensal) }\end{array}$ \\
\hline
\end{tabular}

Fuente: elaboración propia con información de INDEC e IPEC.

\subsection{Estructura y dinámica poblacional de la región de la MA}

Sobre la variable poblacional, un primer indicador muestra que de 1991 a 2010 creció la cantidad de población (14 años o más) de la mayoría de las localidades seleccionadas vinculadas a la producción de MA de las tres provincias. En algunos casos, la mejora de la variación intercensal fue importante (p. ej. Tortugas, Bouquet, Montes de Oca, Arteaga, Arequito, Marcos Juárez y Las Varillas). Incluso, en términos comparativos, la media para las localidades de la región de la MA fue mayor que para las respectivas medias provinciales. 


\subsection{Estructura y dinámica de la población económicamente activa (PEA) y su condición en la región de la MA}

Sobre el comportamiento de la PEA (tasas de actividad, empleo y desocupación) de las localidades seleccionadas vinculadas a la MA, un primer aspecto es que en su análisis diacrónico estas localidades tuvieron una mejoría en sus indicadores. Esto es, entre 2001 y 2010, cuando se aplicaron las políticas regionalistas, aumentaron la tasa de actividad (gráfico 2) y de empleo (gráfico 3), mientras que disminuyó la desocupación (gráfico 4).

Gráfico 2. Evolución de la tasa de actividad $(1991,2001,2010)$ en la región de producción de MA

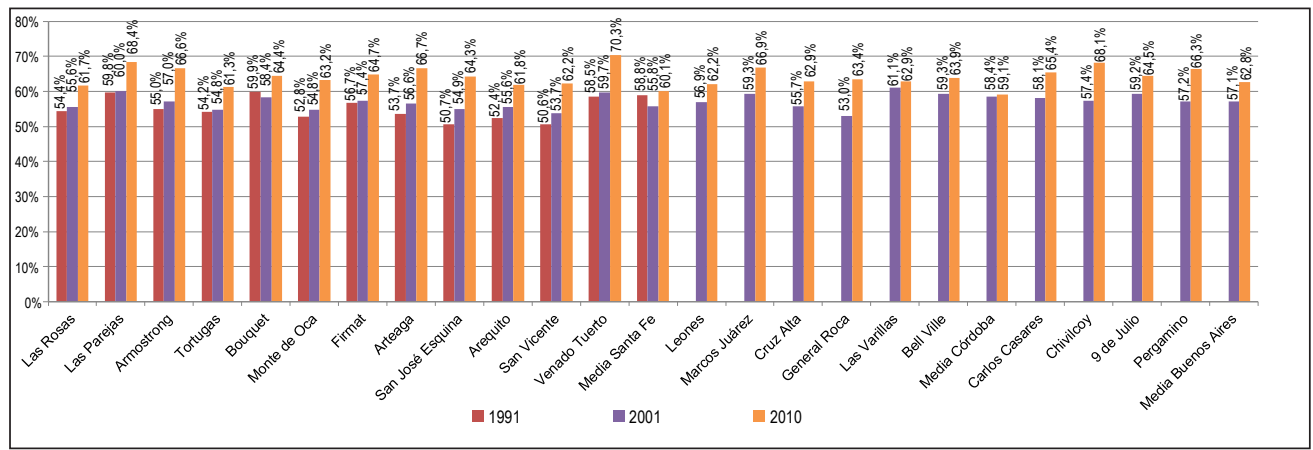

Fuente: elaboración propia con datos del INDEC e IPEC. CNPyV 1991. CNPHyV 2001 y 2010, Redatam +Sp.

Gráfico 3. Evolución de la tasa de empleo (1991, 2001 y 2010) en la región de producción de MA

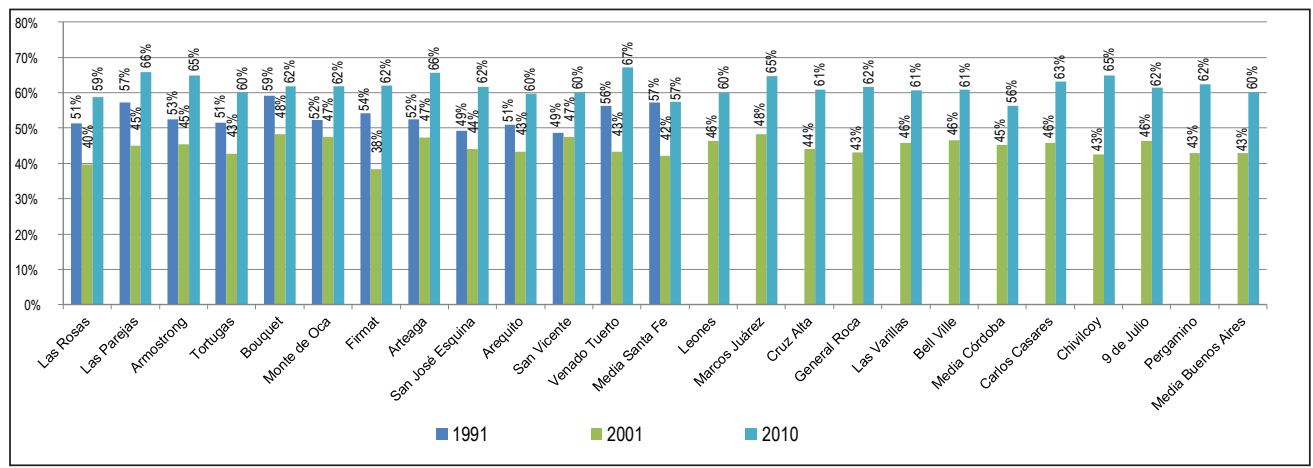

Fuente: elaboración propia con datos del INDEC e IPEC. CNPyV 1991. CNPHyV 2001 y 2010, Redatam +Sp.

El análisis comparado también muestra una leve mejora en las localidades de la MA, tanto con las medias provinciales como respecto a los indicadores de las localidades no vinculadas a esta. Por ejemplo, la tasa de actividad (promedio) de las localidades vinculadas a la región de MA de Santa Fe indicaba un 64,6\% para 
2010; mientras que para aquellas no vinculadas a esta, la tasa era de $59,9 \%$ y la variación intercensal 2001-2010 también favorecía las localidades de la MA. Estas últimas tuvieron una recuperación de la tasa de actividad de 14,3\%, frente al 8,1\% de las localidades no vinculadas a la MA (gráfico 5).

Gráfico 4. Evolución la tasa de desocupación $(1991,2001,2010)$ en la región de producción de MA

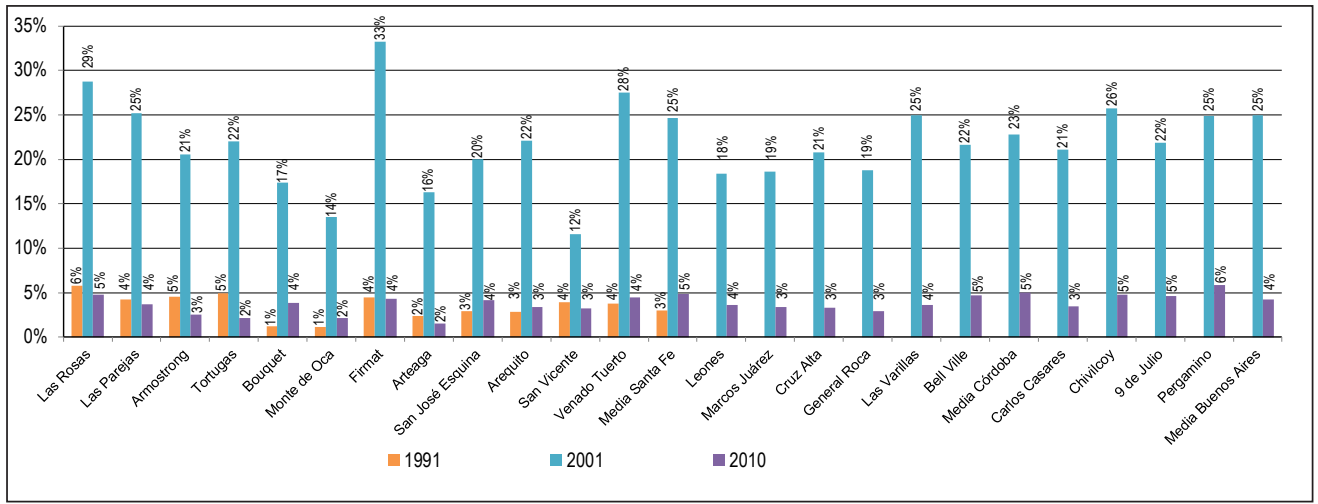

Fuente: elaboración propia con datos del INDEC e IPEC. CNPyV 1991. CNPHyV 2001 y 2010, Redatam +Sp.

Gráfico 5. Comparación de la tasa de actividad (promedio) entre localidades de la MA con el resto de localidades no vinculadas a la MA, por provincia $(1991,2001$ y 2010)

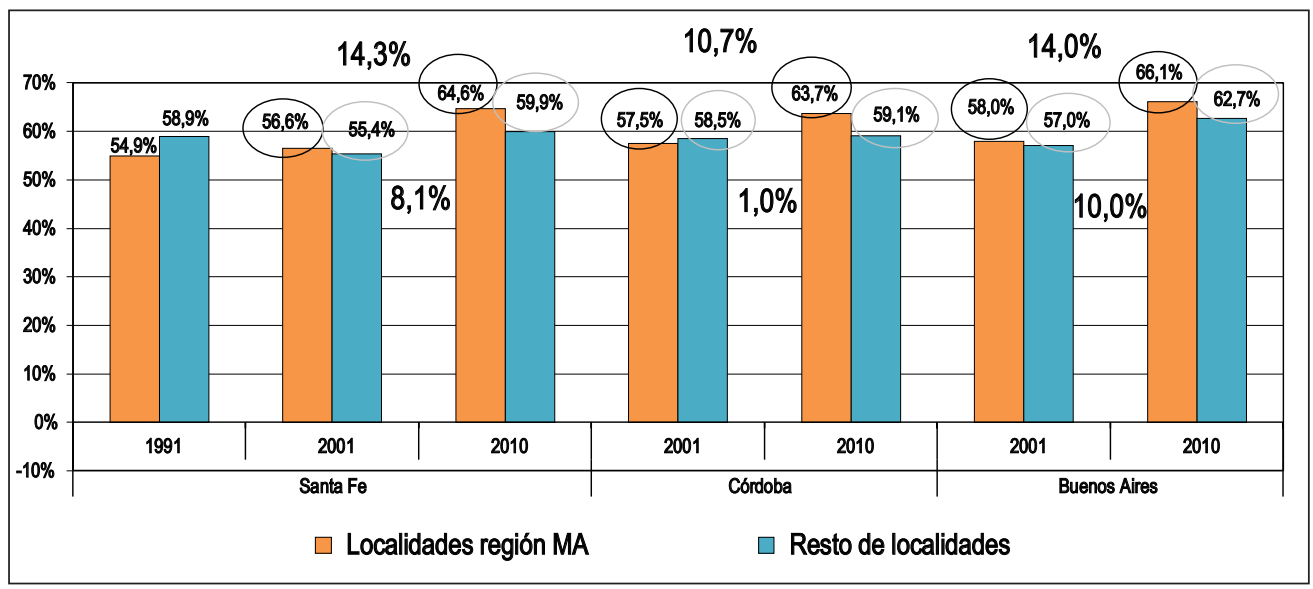

Fuente: elaboración propia con datos del INDEC e IPEC. CNPyV 1991. CNPHyV 2001 y 2010, Redatam +Sp.

Por su parte, la tasa de empleo (promedio) en las localidades vinculadas a la región de MA de Santa Fe pasó de 44,3\% en 2001 a 62,4\% en 2010, esto es, una variación intercensal de 40,9\%; mientras que la tasa de empleo (promedio) de las localidades no vinculadas a dicha región pasó de 41,6\% en 2001 a 57,1\% en 2010, 
es decir, una variación intercensal de 37,3\%. En Córdoba, la tasa de empleo para 2010 es mayor en las localidades de la MA respecto de las no vinculadas a ella (y la variación intercensal también es mayor en las localidades de la MA); y en Buenos Aires, la tasa de empleo para 2010 también es mayor en las localidades de la MA frente a las no vinculadas (y la variación intercensal también es mayor en las localidades de la MA) (gráfico 6).

Gráfico 6. Comparación de la tasa de empleo (promedio) entre localidades de MA con resto de localidades no vinculadas a ella, por provincia $(1991,2001$ y 2010)

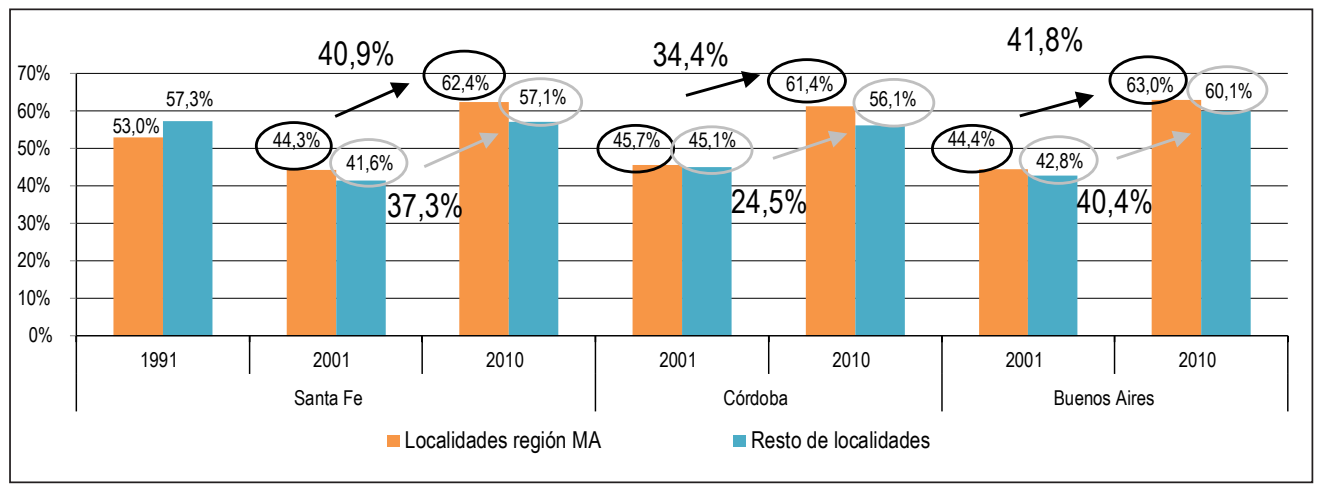

Fuente: elaboración propia con datos del INDEC e IPEC. CNPyV 1991. CNPHyV 2001 y 2010, Redatam +Sp.

Finalmente, la tasa de desocupación también acompañó a las localidades de la MA. Por ejemplo, hacia 2010, las localidades de la MA de Santa Fe mostraron un 3,4\% de desocupación, mientras que las no vinculadas a tal región midieron 4,9\% (con una variación intercensal 2001-2010 de -84,4\% para las vinculadas a la MA y de $80,3 \%$ para las no vinculadas). En Córdoba, la desocupación promedio de las localidades de la MA pasó de 20,5\% en 2001 a 3,6\% en 2010 (disminución de -82,5\%) mientras que en las no vinculadas pasó de 19,3\% en 2001 a 5,0\% en 2010 (variación de -78,0\%). Buenos Aires no mostró mejoras comparadas para las localidades de la MA: la desocupación para 2010 era superior en las localidades de la MA y la variación intercensal muestra una disminución menor de la tasa de desocupación de las localidades de la MA respecto a las no vinculadas (gráfico 7).

\subsection{Estructura y dinámica del nivel de vida de la región de la MA}

El indicador de necesidades básicas insatisfechas (NBI) es un referente utilizado para describir condiciones sociales a partir de medir el nivel de vida de la población, teniendo en cuenta algunos indicadores de lo que se denomina "privación". Los hogares con NBI poseen al menos unas de las siguientes características: hacinamiento, alojamiento en viviendas de tipo inconveniente (pieza de inquilinato o precaria), 
Gráfico 7. Comparación de tasa de desocupación (promedio) entre localidades de la MA con resto de localidades no vinculadas a ella, por provincia (1991, 2001 y 2010)

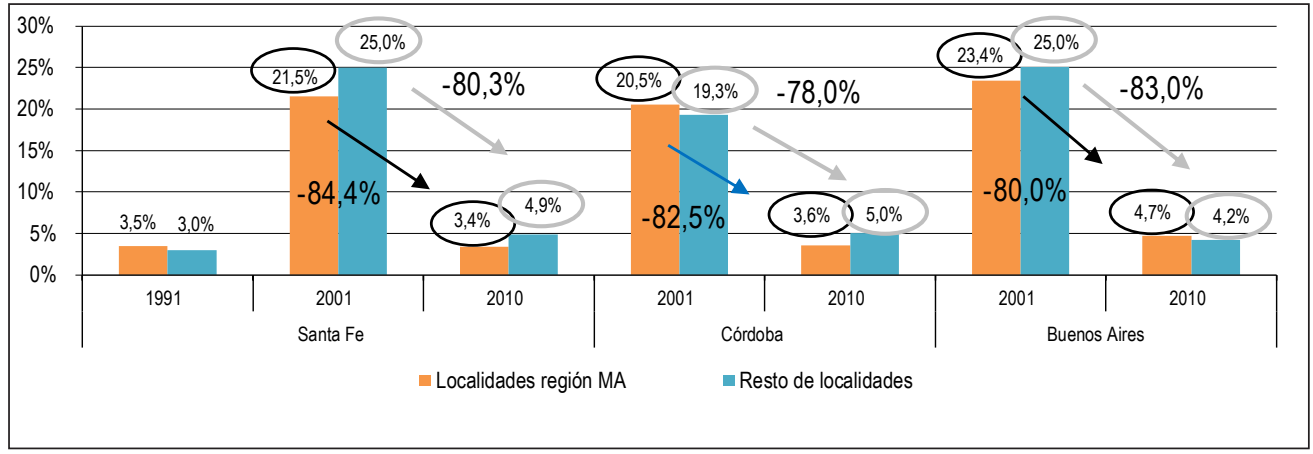

Fuente: elaboración propia con datos del INDEC e IPEC. CNPyV 1991. CNPHyV 2001 y 2010, Redatam +Sp.

hogares sin retrete, deserción escolar de algún niño, o incapacidad de subsistencia (Dirección Nacional de Relaciones Económicas con las Provincias, 2017). Los datos relevados indican una mejoría de las localidades de la producción de MA en sus descripciones diacrónica (gráfico 8) y comparada (gráfico 9). El gráfico 8 muestra el modo progresivo en que disminuyó la cantidad porcentual de hogares con algún indicador de NBI en las localidades de la región de la MA; incluso la disminución es significativa en el periodo intercensal 2001 - 2010 (una disminución de hogares con NBI significa, en principio, una mejora social).

Gráfico 8. Evolución del porcentaje de hogares con algún NBI (1991, 2001, 2010) en la región de producción de MA

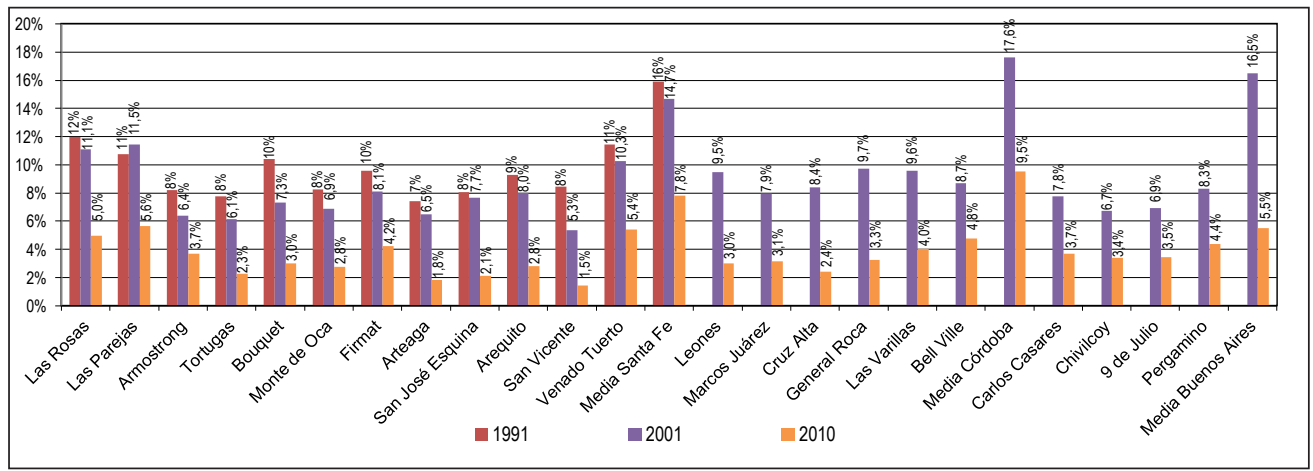

Fuente: elaboración propia con datos del INDEC e IPEC. CNPyV 1991. CNPHyV 2001 y 2010, Redatam +Sp.

En comparación con lo anterior, el porcentaje de hogares con NBI de la región de MA en 2010 fue menor que los porcentuales del resto de las localidades no vinculadas a la MA en las tres provincias: en Santa Fe, 3,3\% frente a 8,0\%; en Córdoba, 
3,4\% frente a 9,6\%; y en Buenos Aires, 3,7\% frente a 5,5\%) (gráfico 9). Incluso las variaciones intercensales, a excepción de Buenos Aires, fueron mejores en las localidades de la MA que en el resto de las localidades no vinculadas a ella, es decir, disminuyó la cantidad de hogares con NBI entre 2001 y 2010 (gráfico 9).

Gráfico 9. Comparación de porcentaje de hogares con NBI entre localidades de MA con resto de localidades no vinculadas a la MA (por provincia): 1991, 2001 y 2010

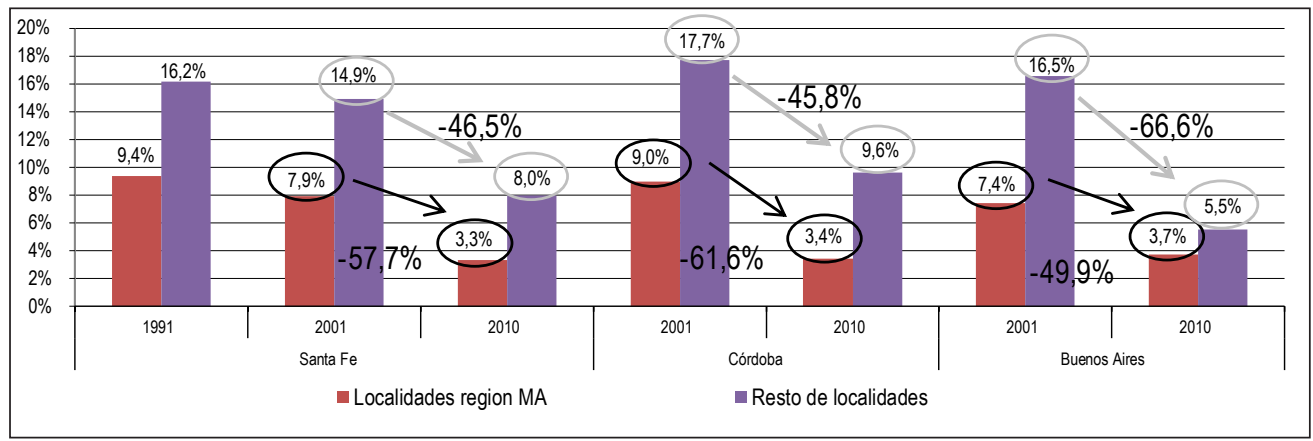

Fuente: elaboración propia con datos del INDEC e IPEC. CNPyV 1991. CNPHyV 2001 y 2010, Redatam +Sp.

\subsection{Estructura y dinámica de los indicadores de educación de la región de la MA}

En lo que atañe a la situación de la región vinculada a los indicadores de educación, se seleccionaron la tasa de analfabetismo y el nivel de instrucción de la población como descriptores del comportamiento. La descripción de los datos repite lo visto antes: en términos diacrónicos, las localidades vinculadas a la producción de MA tuvieron mejoras sucesivas intercensales. Por ejemplo, en la tasa de analfabetismo, los datos muestran una disminución de este último entre 1991, 2001 y 2010 (gráfico 10).

Gráfico 10. Evolución de la tasa de analfabetismo $(1991,2001,2010)$ en la región de la MA

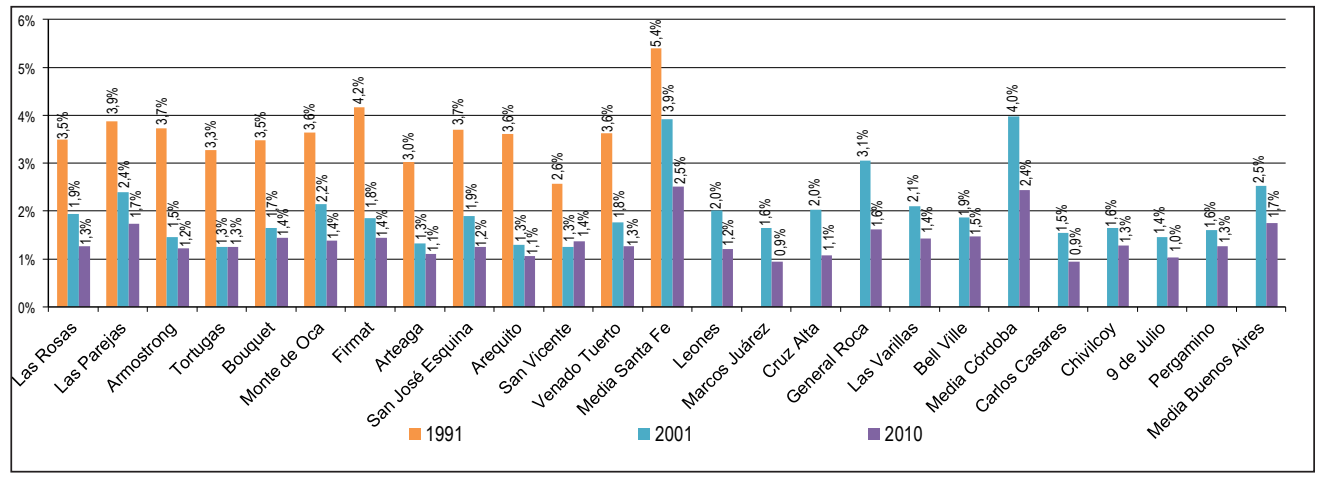

Fuente: elaboración propia con datos del INDEC e IPEC. CNPyV 1991. CNPHyV 2001 y 2010, Redatam +Sp. 
En el análisis comparado, las localidades de la MA estuvieron por debajo del comportamiento de sus respectivas medias provinciales. A su vez, el grupo de localidades vinculadas a la MA tuvo menor índice de analfabetismo promedio para 2010 en las tres provincias (gráfico 11), aunque la tasa de variación intercensal es menor en las localidades de la MA respecto del grupo de localidades no vinculadas a la MA (resto de localidades). Por ejemplo, en Santa Fe, la variación intercensal $2001-2010$ de las localidades vinculadas a la MA fue de -22,1\%, frente a -36,1\% en las no vinculadas. Algo similar ocurre en Buenos Aires, así como en Córdoba. Es decir, en general, las localidades de la región de la MA ostentaron una disminución menor en la tasa de analfabetismo que el grupo de localidades no vinculadas a la MA entre 2001 y 2010 (gráfico 11).

Gráfico 11. Comparación de tasa de analfabetismo entre localidades vinculadas a la MA y resto de localidades no vinculadas a ella, por provincia $(1991,2001$ y 2010)

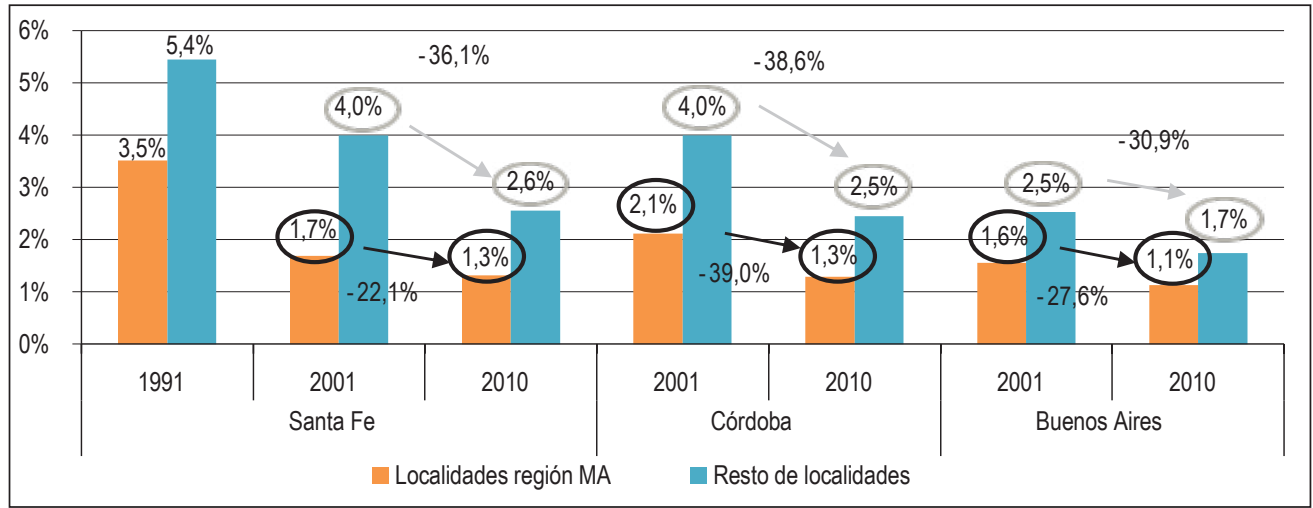

Fuente: elaboración propia con datos del INDEC e IPEC. CNPyV 1991. CNPHyV 2001 y 2010, Redatam +Sp.

Por su parte, respecto del otro indicador de educación, el nivel de instrucción (en este caso se toma el "secundario completo"), los datos muestran varios asuntos. Primero, en el análisis diacrónico, no ha existido un comportamiento uniforme o distintivo de las tasas entre todas las localidades de la MA durante las variaciones intercensales, pues en algunas localidades aumentó el nivel de instrucción para 2010 frente a 2001, mientras que en otras disminuyó (gráfico 12); aunque el 70\% de las localidades de la MA logró que este aumentara. Segundo, en el análisis comparado, en todos los casos los valores de las localidades de la MA son mejores para 2010 que sus respectivas medias provinciales (gráfico 12).

Tercero, también en el análisis comparado, se visualiza que los valores de las localidades vinculadas a la MA tienen un mayor nivel de instrucción para 2010 que el nivel de las localidades no vinculadas a ella (gráfico 13). Y cuarto, las variaciones 
intercensales del grupo de localidades de la MA fueron mejores que las del grupo de localidades no vinculadas a ella. Incluso estas últimas tuvieron un comportamiento negativo: disminuyeron el nivel de instrucción para 2010 frente a 2001 en las tres provincias (gráfico 13).

Gráfico 12. Evolución del nivel de instrucción alcanzado (secundario completo) (1991, 2001, 2010) en la región de producción de MA

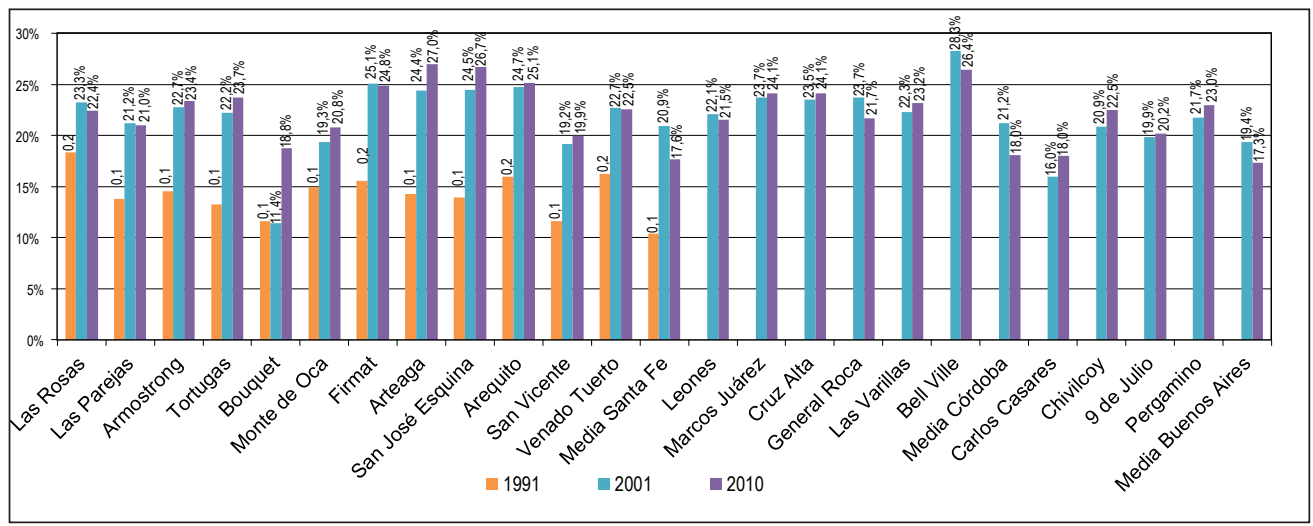

Fuente: elaboración propia con datos del INDEC e IPEC. CNPyV 1991. CNPHyV 2001 y 2010, Redatam +Sp.

Gráfico 13. Comparación del nivel de instrucción (secundario completo) entre localidades de la MA con resto de localidades no vinculadas a MA (por provincia): 1991, 2001 y 2010

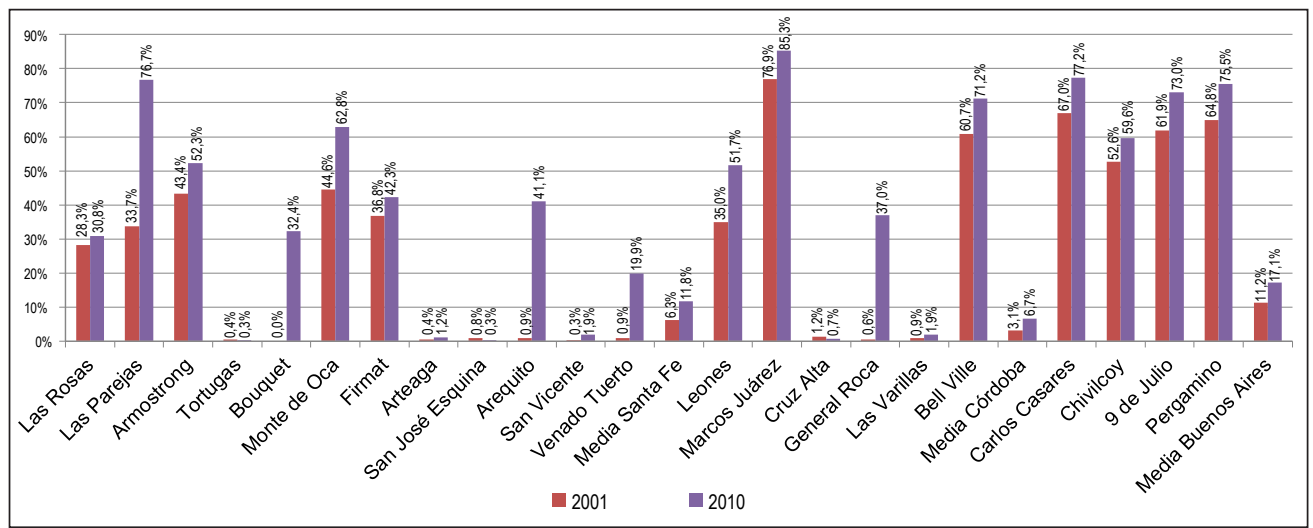

Fuente: elaboración propia con datos del INDEC e IPEC. CNPyV 1991. CNPHyV 2001 y 2010, Redatam +Sp.

\subsection{Estructura y dinámica de los indicadores de salud de la región de la MA}

La estructura y la dinámica de la variable de salud se describen con relación a dos indicadores utilizados para estas mediciones: 
- Agua potable y saneamiento básico: mide el comportamiento del porcentaje de viviendas que cuentan con inodoro con descarga y desagües (saneamiento básico), y con agua potable de red pública sobre la cantidad de viviendas de cada localidad.

- Cobertura de salud: mide el porcentaje de personas que cuentan con una obra social, un plan de salud privado, mutual o prepago, o se encuentran recibiendo un programa o plan estatal de salud.

En términos diacrónicos, los datos de saneamiento básico muestran que las localidades vinculadas a la producción de MA tuvieron mejoras intercensales sucesivas (gráfico 14). En términos comparados, los valores de las localidades de la MA, tanto para 2001 como para 2010, fueron (en general) mejores que los valores de sus respectivas medias provinciales (gráfico 14).

Gráfico 14. Evolución de agua potable y saneamiento básico $(2001,2010)$ en la región de producción de MA

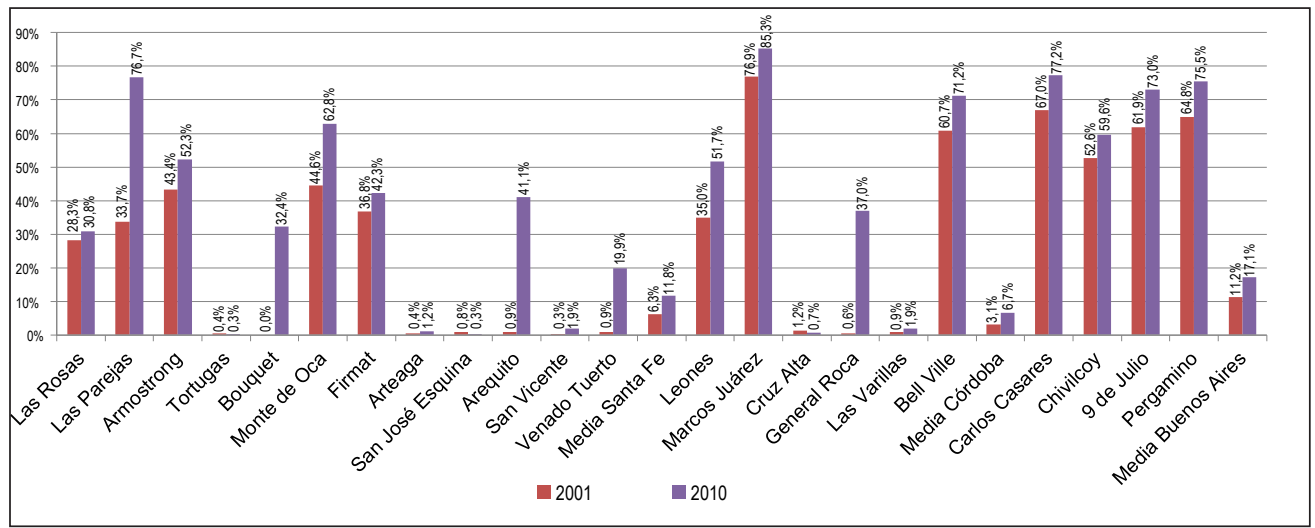

Fuente: elaboración propia con datos del INDEC. CNPHyV 2001 y 2010, Redatam +Sp.

A su vez, el nivel de saneamiento básico de las localidades vinculadas a la MA para 2010 fue superior al grupo de localidades no vinculadas a ella, denominado "resto de las localidades", en las tres provincias (gráfico 15). El único indicador que no es homogéneo es la tasa de variación intercensal entre 2001 y 2010, que presenta diferencias entre las localidades vinculadas y no vinculadas a la MA, entre provincias (gráfico 15).

En cuanto la información a la cobertura de salud, en 2010 fue relevada por el cuestionario ampliado del CNPHyV. Entonces, al procesar los datos con Redatam+SP, no se puede obtener la información por localidad; si es el caso para municipio, entonces la información utilizada es obtenida por municipio. Esto trajo la complicación 
de que, en el caso de Buenos Aires el municipio es el partido, y este difiere mucho de una localidad por ello se prefirió no relevar la información para Buenos Aires (se mantuvo la estructura de gráfico que se venía presentando para no alterar la visual y la comprensión del grafico por el lector).

Gráfico 15. Comparación de agua potable y saneamiento básico entre localidades de la MA con resto de localidades no vinculadas a la MA (por provincia): 2001 y 2010

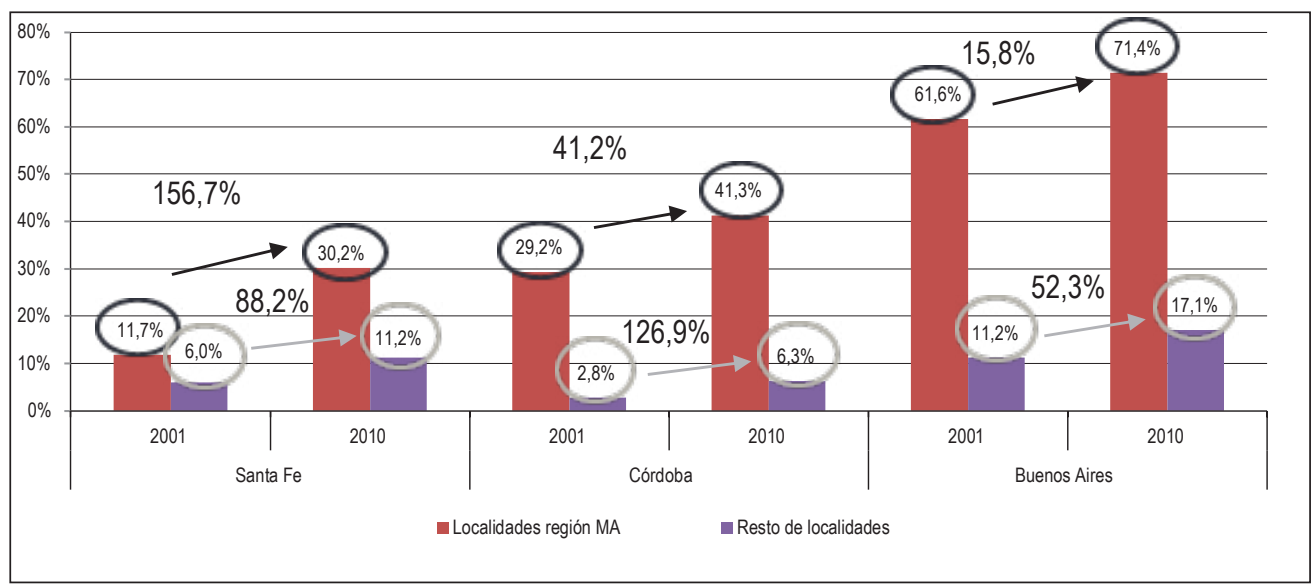

Fuente: elaboración propia con datos del INDEC. CNPHyV 2001 y 2010, Redatam +Sp.

Los datos de cobertura de salud evidencian tres asuntos: primero, en el análisis diacrónico, los valores muestran que aumentó el porcentual de cobertura de salud en todas las localidades para 2010 frente a 2001 (gráfico 16); segundo, en el análisis comparado, en todos los casos los valores de las localidades de la MA son mejores para 2010 que sus respectivas medias provinciales (gráfico 16).

Gráfico 16. Evolución de la cobertura de salud $(2001,2010)$ en la región de producción de MA

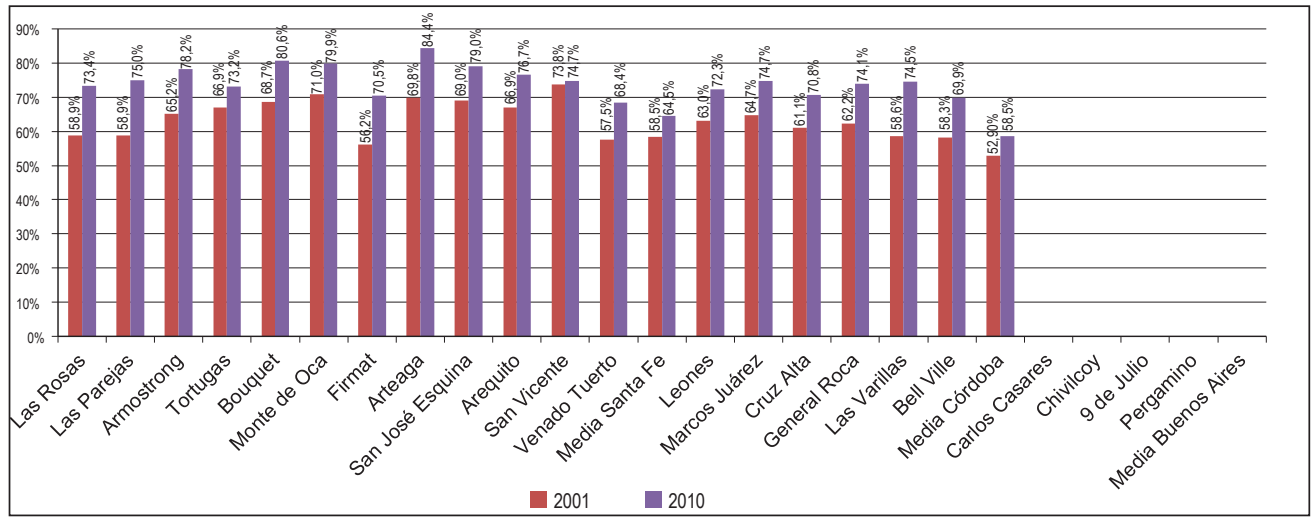

Nota: no existen datos disponibles para las localidades de Buenos Aires.

Fuente: elaboración propia con datos del INDEC. CNPHyV 2001 y 2010, Redatam + Sp. 
En tercer lugar, también en el análisis comparado, los valores de las localidades de la MA han tenido un mayor nivel de instrucción para 2010 frente a las no vinculadas (gráfico 17). Y en cuarto lugar, incluso las variaciones intercensales del grupo de localidades vinculadas a la MA fueron mejores que aquellas del grupo de localidades no vinculadas a la ella (gráfico 17).

Gráfico 17. Comparación de la cobertura de salud entre localidades de la MA y resto de localidades no vinculadas a ella, por provincia (2001 y 2010)

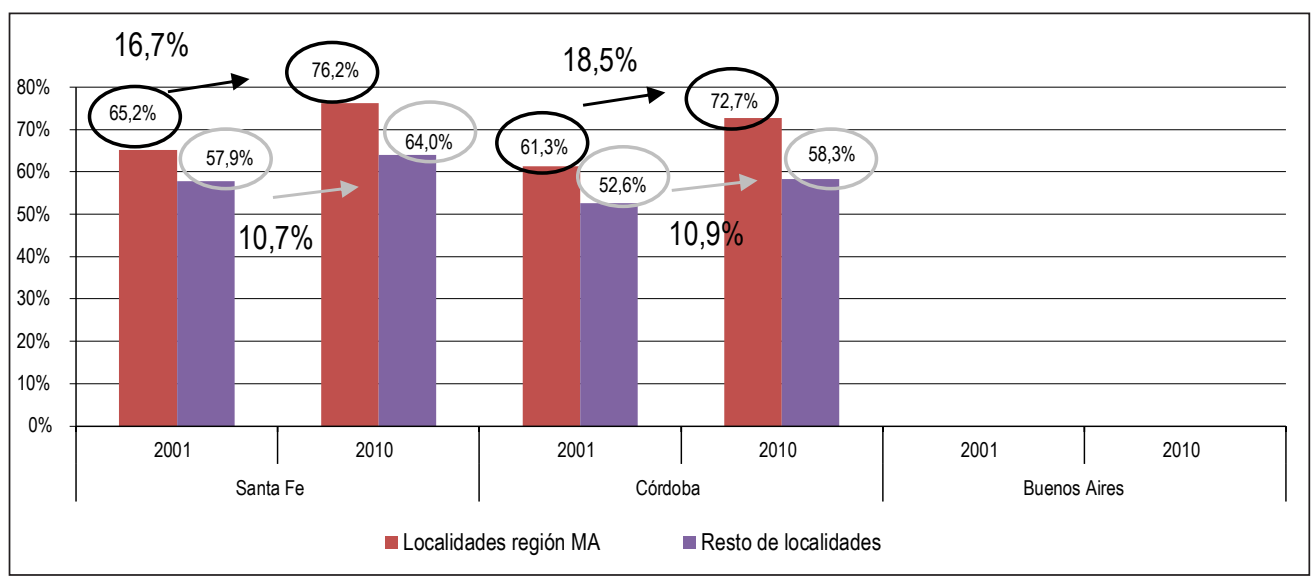

Nota: no existen datos disponibles para las localidades de Buenos Aires.

Fuente: elaboración propia con datos del INDEC. CNPHyV 2001 y 2010, Redatam +Sp.

\section{REFLEXIONES SOBRE LAS POLÍTICAS DE DESARROLLO ECONÓMICO REGIONAL Y EL CASO DE LA MA ARGENTINA}

Este trabajo planteó un análisis exploratorio en Argentina sobre la manera en que se conforma una región económica, la forma como en dicha construcción se articulan políticas nacionales y regionales, y los impactos sociales derivados de esas políticas. Se mostró que la región de la MA argentina se posicionó con fuerza en el mapa político y económico argentino durante el modelo nuevo desarrollista luego de 2001, a partir de un fuerte impulso desde el Estado nacional y en el marco de un nuevo esquema de acumulación, en el que el Estado intentó articular políticas con otras instancias regionales y locales vinculadas a la producción de MA; y que, en esa articulación de políticas e instituciones, se visualizó un nuevo espacio regional.

Se propuso también revisar en esa región algunos impactos sociales de las políticas económicas implementadas. En esta exploración, se detectó que existió una mejoría o evolución positiva hacia 2010 (respecto de 2001) de la mayoría de los indicadores seleccionados para analizar el comportamiento de las condiciones so- 
cioeconómico-demográficas de la región de la MA argentina que recibió políticas económicas de desarrollo regional. A su vez, los resultados positivos de los indicadores sociales se repitieron cuando se analizó de forma comparada la región de la MA con los datos de la media provincial y los del resto de localidades no vinculadas a la producción de MA. Es decir, los indicadores de las dinámicas sociales de la región de la MA se comportaron mejor que los de las medias provinciales y los de las localidades no vinculadas a ella.

El análisis permite inferir que el cambio macroeconómico y político experimentado en Argentina desde 2001 (con posterioridad a la crisis institucional), que dio paso a la aparición de la región de la producción de MA, receptora de una gran cantidad de políticas de desarrollo económico regional, se corresponde también con una mejoría en los indicadores sociales regionales durante el periodo 2001-2010. Dicho de otra manera, el tipo de política macroeconómica, sectorial y económica regional desplegada durante la década del 2000 parece tener un correlato positivo en los indicadores seleccionados para describir las dinámicas sociales de la región identificada como productora de MA argentina. En ese sentido, el ejercicio propuesto en el trabajo habilita unas breves reflexiones finales, las cuales se presentan a continuación.

En primer lugar, se han hecho muchas conjeturas sobre la idea de la simultaneidad temporal y espacial entre dinámicas económicas y sociales: por ejemplo, se ha indicado que los resultados "sociales" pueden ser causados por una gran variedad de políticas (sociales) o factores, más allá de las políticas económicas regionales específicamente desplegadas para la $\mathrm{MA}^{15}$; o que las mediciones intercensales no son momentos adecuados para medir las diferentes aplicaciones de políticas que dan lugar a mejoras sociales; o incluso que es difícil establecer una geografía territorial de las mejoras sociales ocurridas (por la movilidad del mercado de trabajo), entre muchas otras. Sin embargo, no debería descuidarse la búsqueda de relaciones más directas entre dinámicas económicas y dinámicas sociales regionales.

Este aspecto va en línea con una reciente discusión sobre las políticas y estrategias de intervención sobre el desarrollo. Por un lado, los enfoques espacialmente neutrales como el del Banco Mundial (World Bank, 2009), que trabajan sobre las ventajas económicas derivadas de los efectos de las aglomeraciones espaciales sin

\footnotetext{
${ }^{15}$ Ciertamente, se ha observado en particular que debería prestarse atención a que los impactos sociales pueden provenir del alto precio de los commodities en los mercados internacionales. Sin embargo, la existencia de factores exógenos eventualmente favorables solo se vuelve favorable en tanto y en cuanto sean efectivamente aprovechables, por ejemplo, por la promoción de un tipo de cambio conveniente para esos commodities y un esquema redistributivo que derrame las posibles ventajas generadas en la dinámica de acumulación.
} 
Política económica regional e impactos sociales: el caso de la maquinaria agrícola argentina

demasiadas consideraciones particulares sobre el espacio concreto (y sus características histórico-sociales) en donde se producen, suelen entender que la concentración económica es inevitable y que, en definitiva, favorece el desarrollo general (a escala nacional), por lo que cualquier política o medida tendiente a evitar la concentración o restringirla sería contraproducente. Sugieren que es necesario acompañar (con instituciones apropiadas) esa concentración y complementarla, sobre todo con mayor conectividad y movilidad hacia y desde esas grandes aglomeraciones, de manera que existan "vasos comunicantes" que nivelen los flujos de mano de obra y riqueza entre los espacios concentrados y rezagados, de tal modo que se reviertan "naturalmente" las eventuales inequidades regionales. El foco está puesto en potenciar a las personas -antes que a los lugares-, su capacidad, su movilidad y su habilidad transformadora, independientemente de donde estén ubicadas, pues se moverán y ubicarán en los lugares donde "naturalmente" deban hacerlo.

Por su parte, los regionalistas más heterodoxos vienen proponiendo políticas para el desarrollo económico regional, denominadas "basadas en el lugar" (Barca, 2009), que descansan en la capacidad movilizadora de las instituciones, en sinergia con la geografía economía local, y de las situaciones específicas del contexto (geográfico e histórico) de cada lugar. Las versiones más modernas de esta línea conceptual intentan articular la capacidad de movilidad del agente "externo" (nacional o global) con la del agente "interno" (actor local) cuya coordinación (nada fácil) se vuelve esencial para activar de la mejor manera los procesos de desarrollo regional. Este enfoque suele sostener que no es social ni políticamente aceptable la existencia de amplias diferencias económicas y de nivel de bienestar entre las distintas regiones de un país (o incluso de un conjunto de países integrados), ni es éticamente aceptable que una parte de la población deba abandonar sus lugares de origen para conseguir trabajo y un nivel de ingresos aceptable, como lo indica Cuadrado (2010) (véanse también Barca, McCann y Rodríguez-Pose, 2012). En esta última línea, que este trabajo intenta compartir, la búsqueda constante de mejoras sociales y la disminución de las desigualdades interregionales es siempre un objetivo legítimo y primario.

En segundo lugar, debe retomarse la discusión de la relación entre políticas de desarrollo regional, políticas macroeconómicas y políticas sectoriales. En buena medida, el enfoque del desarrollo regional ha venido relegando la discusión sobre la vinculación con los múltiples ámbitos de regulación posibles en la necesidad de descentralizar procesos y desasfixiar a los espacios regionales y locales de la presencia estatal, pues se partía de que las regiones no pueden quedar subordinadas a una estrategia nacional. Empero, debe revertirse esa idea y pensarse a la estrategia de intervención nacional como posibilidad de potenciar las diferentes formas 
socioespaciales regionales. La instancia nacional tiene un rol estratégico en el mantenimiento del equilibrio o balance territorial o regional, así como en la definición de la composición general de la actividad económica nacional (el patrón general de acumulación) para compatibilizarlo en una estrategia nacional regionalista; le correspondería consensuar medidas centrales como las políticas funcionales de economía amplia, monetaria, fiscal, tributaria, de tasas de intercambio, de competitividad, de equilibrio macroeconómico, de niveles promedio de protección general y sectorial, etc., junto con políticas dirigidas a las diferentes formaciones socio-espaciales regionales. El caso argentino visto, y la manera en que el Estado nacional intentó una reversión del esquema de acumulación con posterioridad al 2001, avanzando en la articulación entre la macroeconomía, la política sectorial y la política económica regional, es un buen ejemplo de la posibilidad de repensar el Estado nacional en el desarrollo regional.

En tercer lugar, debe auspiciarse una mayor diversidad de herramientas y polí ticas de regeneración económica regional, atendiendo a las variedades de conformaciones regionales posibles -y de sus características actuales y pasadas- (véanse McCann y Ortega-Argilés, 2013). En la práctica, ha habido una tendencia a fomentar la aglomeración empresarial territorial (llámese clúster, distrito, etc.) como la forma geográfica privilegiada de obtención de competitividad, con lo que se ha generado una homogeneización de las estrategias de regeneración económica bajo el supuesto de que los espacios regionales poseen dinámicas internas innovadoras, colaborativas y autosuficientes, pero obviando toda consideración a la conformación histórica y multigeográfica de cada región, sus potenciales conflictos, el rol de las elites empresariales, y las posibles identidades múltiples regionales, entre otros aspectos. Aquí existe un potencial enorme en las posibilidades abiertas a las conformaciones regionales y en la manera en que deben fomentarse. El caso analizado en Argentina combinó una serie de herramientas macroeconómicas y sectoriales con la tendencia a la repetición de la aglomeración regional de empresas. El resultado de la correlación con las dinámicas sociales fue positivo, aunque no debería descuidarse la búsqueda de herramientas más específicas y con mayores impactos sociales.

\section{REFERENCIAS}

Albornoz, I.; Anlló, G. y Bisang, R. (2010). La cadena de valor de la maquinaria agrícola argentina: estructura y evolución del sector a la salida de la convertibilidad. Colección Documentos de proyectos, $n .^{\circ} 47$, Buenos Aires, Comisión Económica para América Latina y el Caribe - Cepal, 50p.

Allen, J. y Cochrane, A. (2007). Beyond the Territorial Fix: Regional Assemblages, Politics and Power. En: Regional Studies, Vol. 41, n. ${ }^{\circ}$, p. 1161 - 1175. 
Políitica económica regional e impactos sociales: el caso de la maquinaria agrícola argentina

Allen, J.; Massey, D. y Cochrane, A. (1998). Rethinking the Region: Spaces of Neo-Liberalism, 1st Edition. Londres y Nueva York: Routledge, 172p.

Amin, A. (2004). Regions unbound: towards a new politics of place. En: Geografiska Annaler: Series B, Human Geography, Vol. 86, n.․ 1, p. 33-44.

Amin, A. (2008). Regiones sin fronteras. Hacia una nueva política del lugar, p. 333-352. En: V. R. Fernández, A. Amin y J. I. Vigil (Eds.). Repensando el desarrollo regional. Contribuciones globales para una estrategia latinoamericana. Buenos Aires: Facultad de Ciencias Económicas, Universidad nacional del Litoral, 557p.

Barca, F. (2009). An agenda for reformed cohesion policy. A place-based approach to meeting European Union challenges and expectations. Independent Report prepared at the request of Danuta Hübner, Commissioner for Regional Policy, 244p.

Barca, F., McCann, P. y Rodríguez-Pose, A. (2012). The case for regional development intervention: place-based versus place-neutral approaches. En: Journal of Regional Science, Vol. 52, n. ${ }^{\circ}$ 1, p. 134-152.

Bil, D. (2009). La industria argentina de maquinaria agrícola (1870-1975): evolución y problemas de su desarrollo. Documentos de Jóvenes Investigadores, n. ${ }^{\circ}$, Buenos Aires: Instituto de Investigaciones Gino Germani, Facultad de Ciencias Sociales, Universidad de Buenos Aires, 86p.

Bragachini, M. (2008). Crecimiento sostenido de la maquinaria agrícola argentina: mercado interno y exportaciones, Instituto Nacional de Tecnología Agropecuaria (INTA), p. 5-9. En: Gobierno de Santa Fe (2008). Cadena de a maquinaria agrícola santafesina. Argentina, 24p.

Bragachini, M. (2014). Exportaciones de Maquinaria Agrícola (MA) a nivel global y de Argentina: Mercado Interno de Argentina. Análisis y Tendencias al 2020. Córdoba: Instituto Nacional de Tecnología Agropecuaria. INTA Manfredi, 37p.

CECMA (2006). Proyecto integrado del clúster de maquinaria agrícola y agropartes de la región centro de Argentina que integra el conglomerado productivo (PI-TEC). Proyecto No NA 002/06. Las Parejas.

Castellarín, J. L.; Moro, J. I. y Bianchi, P. A. (2003). Producción regional exportable. Potenciación e internacionalización del clúster de Las Parejas. Las Parejas: Consejo Federal de Inversiones (CFI).

Cideter (2009). Reporte de actividades: Agro Show Room 2009 de la Maquinaria Agrícola Argentina. Exportación de maquinaria y tecnología, de la mano de la siembra directa. Las Parejas (Santa Fe): Cideter.

Ciecti. (2013). La producción en red en Argentina y sus fundamentos institucionales. Documento de Trabajo, n.․ 3, Buenos Aires: Centro Interdisciplinario de Estudios en Ciencia, Tecnología e Innovación, 83p.

Cuadrado Roura, J. R. (2010). La política regional y el conflicto eficiencia-equidad. En: Desarrollo regional en América Latina: El lugar importa, CEPAL, Seminarios y Conferencias, n. ${ }^{7} 70$, p. 57-78. 
Fleurbaey, M., y Blanchet, D. (2013). Beyond GDP: Measuring Welfare and Assessing Sustainability, 1st Edition. Oxford: Oxford University Press, 336p.

Gasparetto, E. (1981). Diagnóstico de la industria de la maquinaria agrícola en la Provincia de Santa Fe. Santa Fe: Organización de las Naciones Unidas para el Desarrollo Industrial (Onudi) y Dirección General de Asesoramiento Técnico (DAT), 117p.

Gobierno de Santa Fe, (2008). Cadena de valor de la maquinaria agrícola y sus partes. Una nueva visión para la producción y el desarrollo. Santa Fe: Ministerio de la Producción, Gobierno de la Provincia de Santa Fe.

Goldstein, E. y Lavarello, P. J. (2011). Entre las fallas de mercado y las políticas sectoriales: en búsqueda de una política industrial para el sector de maquinaria agrícola en Argentina. En: Política Industrial, n. ${ }^{\circ} 15$, p. 26-36.

Hybel, D. (2006). Cambios en el complejo productivo de maquinarias agrícolas 1992-2004. Desafíos de un sector estratégico para la recuperación de las capacidades metalmecánicas. Documentos de Trabajo, n. 3, Buenos Aires: Instituto Nacional de Tecnología Industrial (INTI), 62p.

Jones, M. (2016). Polymorphic Political Geographies. En: Territory, Politics, Governance, Vol. 4, n. ${ }^{\circ} 1$, p. $1-7$.

MacLeod, G. y Jones, M. (2007). Territorial, Scalar, Networked, Connected: In What Sense a Regional World? En: Regional Studies, Vol. 41, n. ${ }^{9}$, p. 1177-1191.

McCann, P., y Ortega-Argilés, R. (2013). Modern regional innovation policy. En: Cambridge Journal of Regions, Economy and Society, Vol. 6, n.․ (2), p. 187-216.

Paasi, A. y Metzger, J. (2017). Foregrounding the region. En: Regional Studies, Vol. 51, n. ${ }^{1}$, p. 19-30.

Pike, A.; Rodríguez-Pose, A. y Tomaney, J. (2016). Shifting horizons in local and regional development. En: Regional Studies, Vol. 51, n.1, p. 46-57.

Piñero, F. J.; Herrera, G. y Di Meglio, F. (2011). Los consorcios de exportación como estrategia de inserción internacional. Caso de Estudio: Grupo Asociativo de Productores de Maquinaria Agrícola (Gapma), Provincia de Buenos Aires, Argentina. En: Interações, Vol. 12, n. ํ 1, p. 9- 18.

Pol, M. A. (2011). Medición del desarrollo humano a escala territorial: metodología y su aplicación a los casos de Argentina y México. En: Economía, Sociedad y Territorio, Vol. XI, n. 36, p. 273-315.

Riffo Pérez, L. (2008). Relacionalidad y re-escalamiento: tensiones emergentes para la gobernanza territorial, p. 53-66. En: G. Yáñez Warner, A. Orellana, Ó. Figueroa y F. Arenas (eds.). Ciudad, Poder, Gobernanza. Santiago de Chile: Instituto de Estudios Urbanos, Universidad Católica de Chile, 455p.

Romero Wimer, F. G. (2010). Los fierros vienen marchando ¿̇de dónde vienen? Maquinaria agrícola y capital extranjero en el agro pampeano, 1976-2008. En: Documentos de Trabajo del Centro Interdisciplinario de Estudios Agrarios (CIEA), n. ${ }^{\circ}$, p. 95-117.

Sabel, C. F.; Hybel, D.; Lengyel, M. F. y Lattanzi, R. (2006). Estudio para la reorganización productiva en empresas argentinas manufactureras. Sector Maquinaria Agrícola. Buenos 
Política económica regional e impactos sociales: el caso de la maquinaria agrícola argentina

Aires: Secretaría de Estado de Ciencia y Tecnología (SECyT), Instituto Nacional de Tecnología Industrial (INTI).

Sánchez Domínguez, Á., y Ruiz Martos, M. J. (2013). A multidimensional regional development index as an alternative allocation mechanism of EU Structural Funds remittances, Smart Regions for a Smarter Growth Strategy. Foro anual de la Asociación Española de Ciencia Regional: Smart regions for a smarter growth strategy: new challenges of Regional Policy and potentials of cities to overcome a worldwide economic crisis, Oviedo, España, noviembre 21-22, 32p.

Solanas, C.; Campisi, S. y Risso, E. (2009). El Instituto Nacional de Tecnología Industrial y su participación en la ejecución del acuerdo de cooperación para el desarrollo tecnológico de Venezuela. Buenos Aires: Observatorio de Políticas Públicas, Cuerpo de Administradores Gubernamentales, 41p.

Stiglitz, J.; Sen, A. y Fitoussi, J. P. (2009). Report by the Commission on the Measurement of Economic Performance and Social Progress. Unión Europea: Comisión Europea, 292p.

Vandermotten, C.; Peeters, D. y Lennert, M. (2011). Shaping EU regional policy: looking beyond GDP. Report for The Greens/EFA group in the European Parliament, Green New Deal Series, Vol. 7, Université libre de Bruxelles, 52p.

Varesi, G. Á. (2010). La Argentina postconvertivilidad: modelo de acumulación. En: Problemas del Desarrollo: Revista Latinoamericana de Economía, Vol. 41, n.11, p. 141-152.

Vigil, J. I. (2013). Problemas y desafíos de las teorías y políticas del desarrollo regional en Argentina. En: Revista de Extensión +E, Vol. 3, n.ำ 1, p. 14-23.

Vigil, J. I., y Magri, A. (2015). El problema regional: desarticulaciones regionales y sectoriales en el desarrollo argentino. En: Problemas del Desarrollo: Revista Latinoamericana de Economía, Vol. 46, n.1ㄹ, p. $91-117$.

Widuto, A. (2016). Beyond GDP: Regional Development Indicators. European Union, European Parliamentary Research Service, 12p.

World Bank, (2009). World Development Report 2009: Reshaping Economic Geography. Washington D.C., World Bank, 410p. 


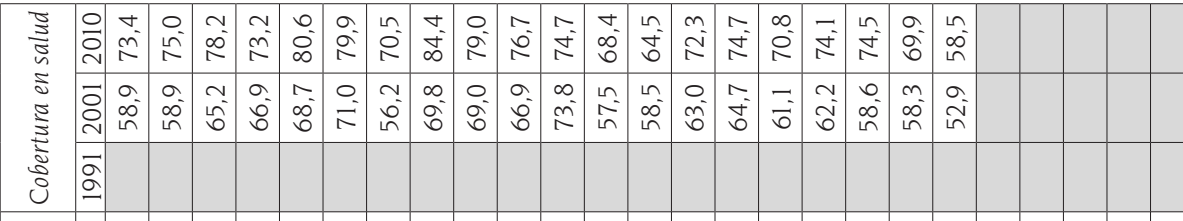

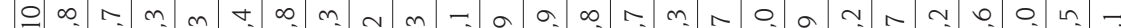
\&

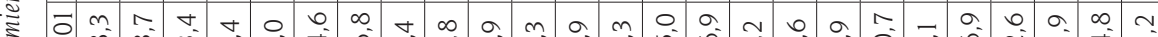

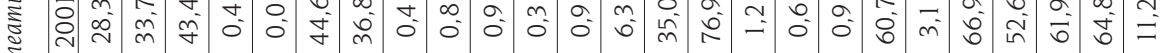
फे

은

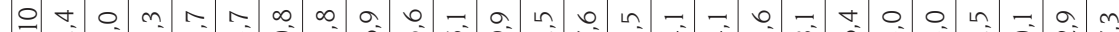

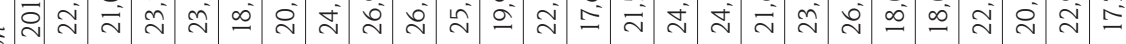
$\approx$ :

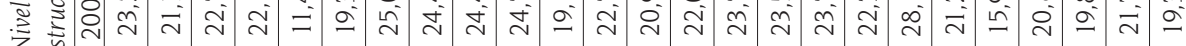

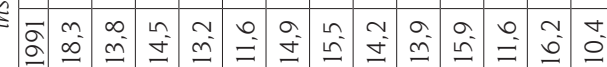

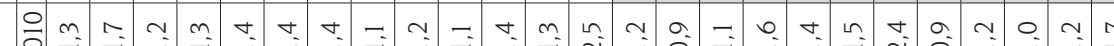

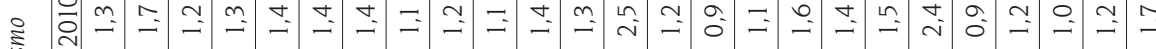

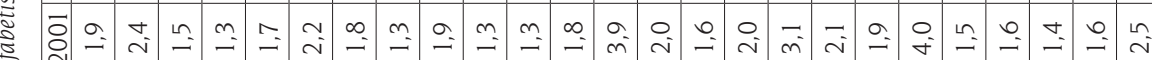

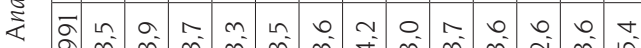

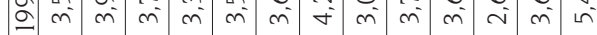

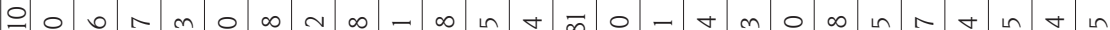

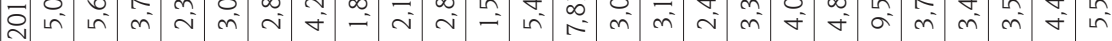

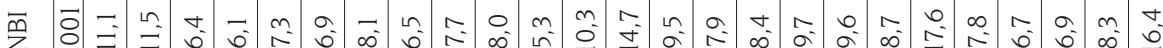
$\begin{array}{llllllllll} & 0 & 0 & \infty & 0\end{array}$

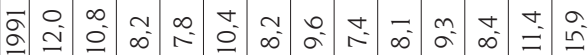

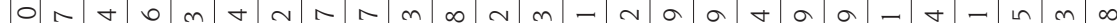

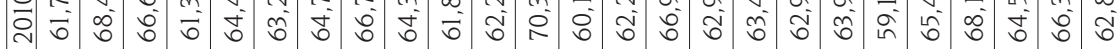

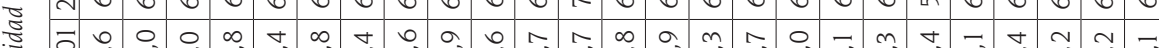
E Di

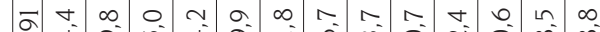

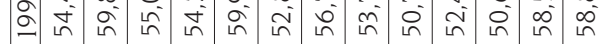

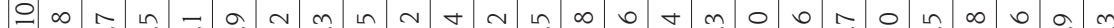
:

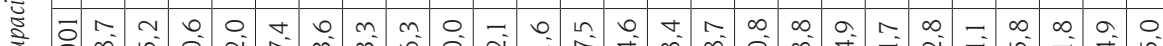

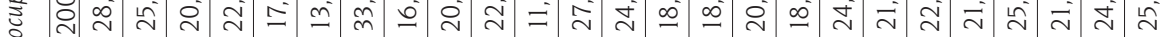
๑ั

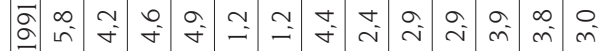

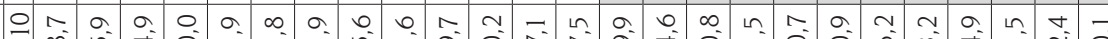
규 象

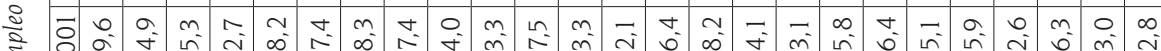
竞

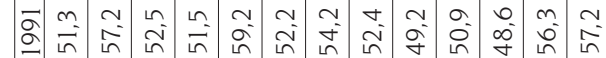

